\title{
Recommended Guide for Determining and Reporting Uncertainties for Balances and Scales
}

\author{
Val Miller \\ State Laboratory Program \\ Weights and Measures Division \\ National Institute of Standards and Technology \\ Technology Administration \\ U.S. Department of Commerce
}





\title{
Recommended Guide for Determining and Reporting Uncertainties for Balances and Scales
}

\author{
Val Miller \\ State Laboratory Program \\ Weights and Measures Division \\ National Institute of Standards and Technology \\ Technology Administration \\ U.S. Department of Commerce
}

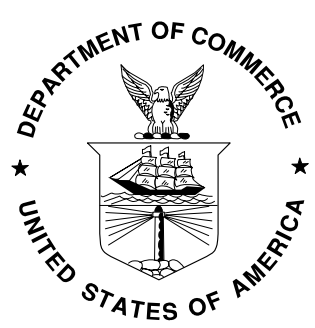

\section{U.S. DEPARTMENT OF COMMERCE}

Donald L. Evans, Secretary

TECHNOLOGY ADMINISTRATION

Phillip J. Bond, Under Secretary of Commerce for Technology NATIONAL INSTITUTE OF STANDARDS AND TECHNOLOGY Arden L. Bement, Jr., Director 



\section{Preface}

The Recommended Guide to Determining and Reporting Uncertainties for Balances and Scales was developed to meet the need expressed by members of the scale service community who were attempting to comply with quality system requirements contained in QS9000, and ISO/IEC 17025, for an interpretive document applying the concepts contained in the Guide to the Expression of Uncertainty in Measurement (GUM) to scale and balance calibrations.

Acknowledgement:

Special thanks regarding this Recommended Guide are given to Georgia Harris, NIST Weights and Measures Division, who originally responded to inquiries and suggested possible solutions and provided technical and editorial guidance, and to Jeffery Horlick, NIST Standards Services Division, who provided technical and editorial comment throughout the process of generating this document. Thanks is also given to those members of the scale service community and NIST WMD office staff who contributed to the creation of the Recommended Guide by providing feedback as to the workability and understandability of the text from the field service perspective and by answering the author's many questions.

These include:

Charles Francis, Mettler Toledo, Inc., Mark Ruefenacht, Heusser Neweigh, Bernd Damm, Deka Scale, Inc., Terry Benjamin, Grand Rapids Scale Company, Inc., Henry Meyers, Antibus Scales and Systems, Inc., Aaron Aldinger, Aldinger Company, Julie Beffrey, Cech Corporation, Richard Suiter, NIST Weights and Measures Division, Tina Butcher, NIST Weights and Measures Division, and Kenneth Butcher, NIST Weights and Measures Division.

Additionally, thanks must go to the writers of the many reference documents for their varied approaches to the calculation of measurement uncertainty. Those works are listed in the bibliography contained in Appendix B. 


\section{Recommended Guide for Determining and Reporting Uncertainties for Balances and Scales}

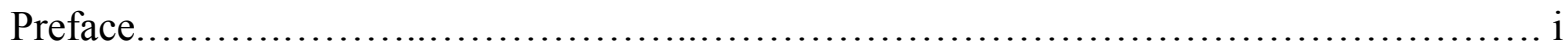

Chapter 1: Purpose \& Background ................................................................................. 1

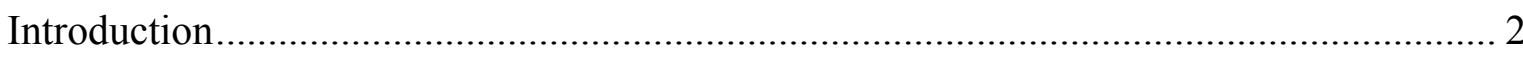

Scope

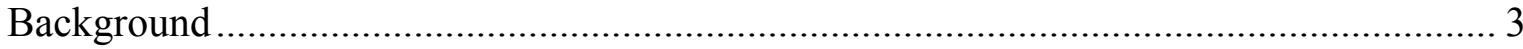

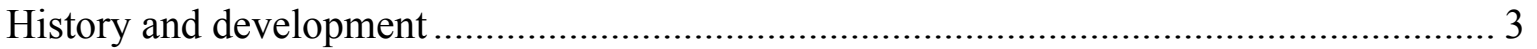

Chapter 2: General concepts ....................................................................................... 7

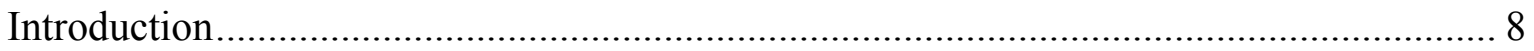

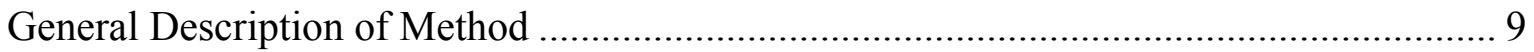

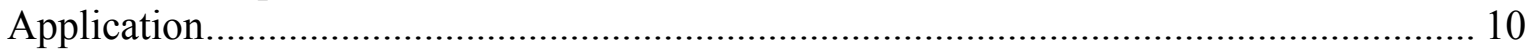

Chapter 3: Balance Calibrations in a Laboratory Environment................................................ 13

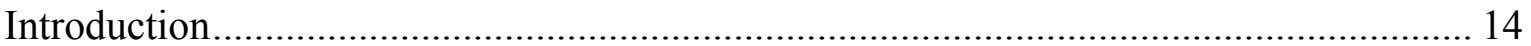

1. Specify the Process and Equation........................................................................... 14

2, 3 \& 4. Uncertainty Identification, Characterization and Quantification........................ 14

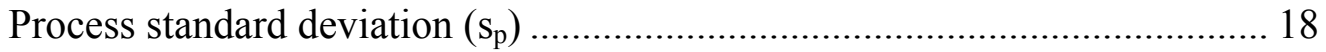

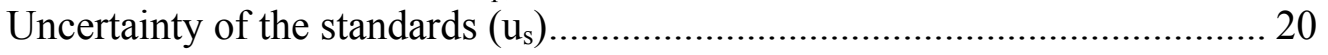

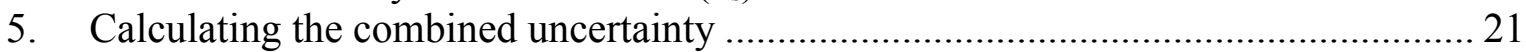

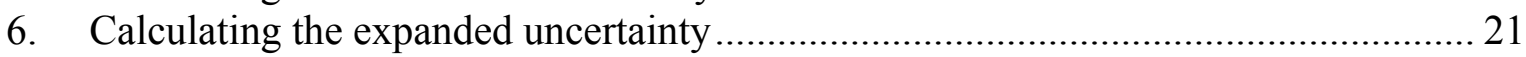

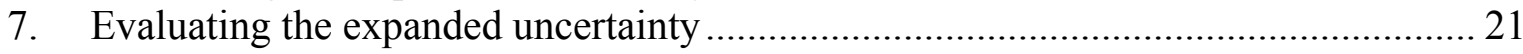

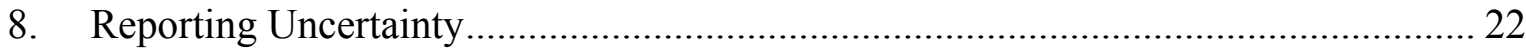

Quick Guide for Laboratory Balance Calibration Uncertainties ........................................ 25

Uncertainty Worksheet ……………………………............................................... 26

Chapter 4: Scale Calibrations Performed in an Uncontrolled Environment.......................... 27

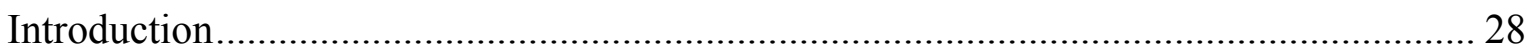

Scales in an uncontrolled environment ................................................................... 28

1. Specify the Process and Equation ......................................................................... 28

2,3 \& 4. Uncertainty Identification, Characterization and Quantification........................ 28

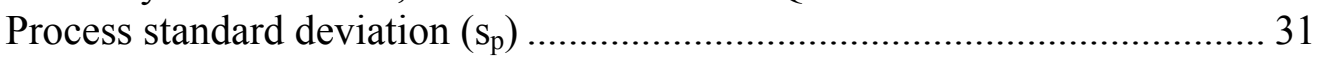

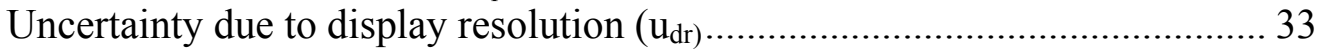

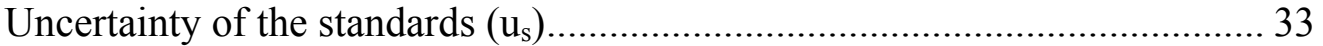

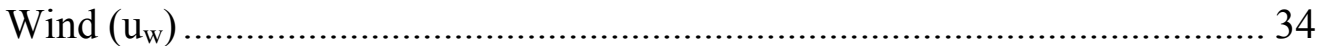

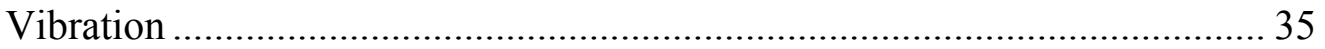

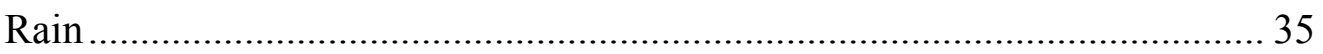

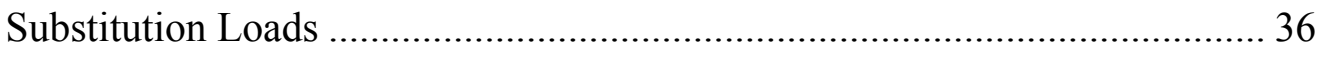

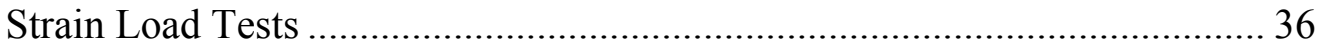

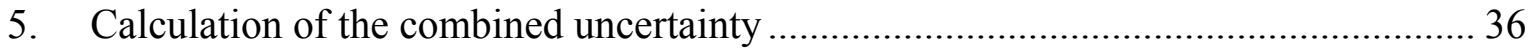

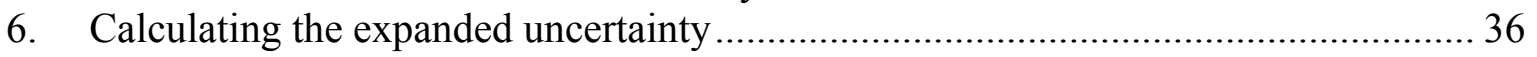

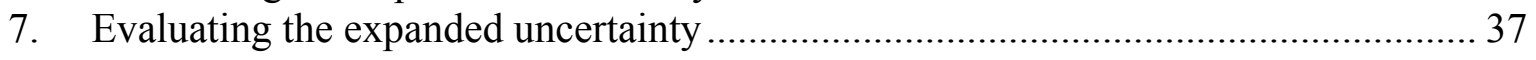

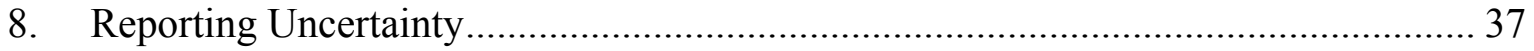

Quick Guide for Scale Calibration Uncertainties .............................................................. 39 


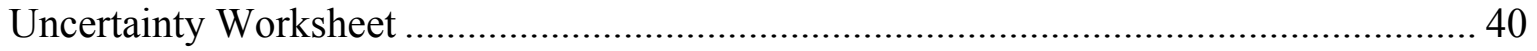

Chapter 5: Scale Calibrations in a Semi-Controlled Environment .......................................... 41

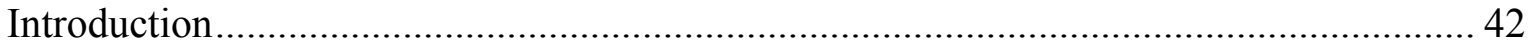

1. Specify the Process and Equation ........................................................................... 42

2, 3 \& 4. Uncertainty Identification, Characterization and Quantification......................... 42

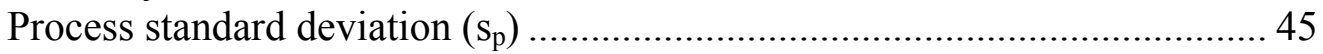

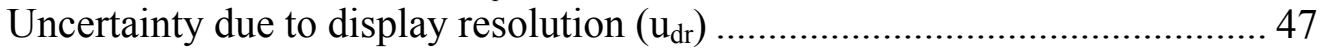

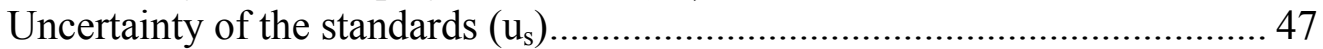

5. Calculation of the combined uncertainty …………................................................... 48

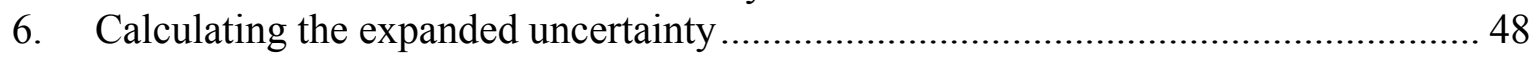

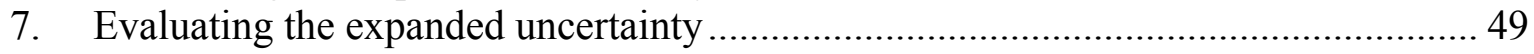

8. Reporting Uncertainty ....................................................................................... 49

Quick Guide for Scale Calibration Uncertainties ......................................................... 51

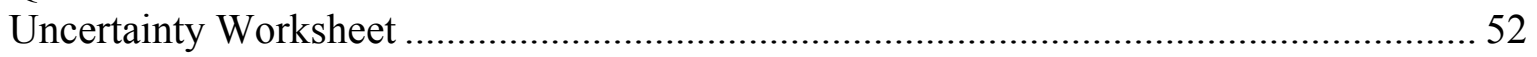

Chapter 6: Sample Calculations and Recommendations for Reducing Uncertainty .............. 53

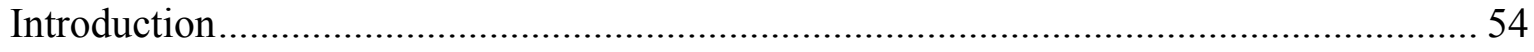

Sample Uncertainty Calculation \#1 (Relates to Chapter 3) ................................................ 54

Sample Uncertainty Calculation \#2: (Relates to Chapter 4)............................................... 59

Changes Needed in Current Calibration Procedures to Address Uncertainty ..................... 66

Appendix A Common Terminology and Definitions ........................................................... 67

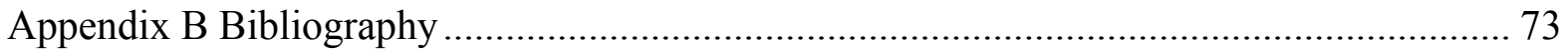


Chapter 1

\section{Chapter 1: Purpose \& Background}




\section{Chapter 1}

\section{Introduction}

The goal of this guide is to provide service personnel with a method for identifying and quantifying the uncertainty components for scale and balance calibrations in both the field and laboratory environments. This guide includes specific information regarding uncertainty in on-site calibration of laboratory balances and large capacity scales. Information compiled from the many reference documents has enabled the writing of this guide; a comprehensive bibliography provides supplementary reading.

\section{Scope}

The Recommended Guide to Determining and Reporting Uncertainties for Balances and Scales provides a useful methodology to enable service personnel to identify, quantify, evaluate, combine and report the uncertainty components most likely to be encountered during the calibration of a scale or balance. The guide cannot be all-inclusive, since each calibration is unique, but it identifies the most common uncertainty contributors and attempts to educate the user so that less significant or less frequently encountered uncertainty contributors may also be identified and included in an expanded uncertainty statement.

This Guide does not address scale and balance calibration methods. Procedural and specification documents for the testing of scales and balances have been in place for quite some time in the form of:

- OIML R 76-1, "Nonautomatic weighing instruments, Part1: Metrological and technical requirements-Tests",

- ASTM E 319-85, "Standard Practice for the Evaluation of Single-Pan Mechanical Balances",

- ASTM E 898-88, "Standard Method of Testing Top-Loading, Direct-Reading Laboratory Scales and Balances",

- ASTM E 1270-88, "Standard Test Method for Equal-Arm Balances";

- NIST Handbook 44, "Specifications, Tolerances, and Other Technical Requirements for Weighing and Measuring Devices", and

- $\quad$ NIST Handbook 112, "Examination Procedure Outlines for Commercial Weighing and Measuring Devices."

However, these procedural documents do not provide adequate instructions to complete a valid uncertainty analysis, hence should be updated by the standards writing community to include specific information regarding calibration uncertainty analyses.

Scale and balance service personnel who perform calibrations are required to properly identify a weighing device and to follow a calibration procedure similar to those listed above. This guide will assist balance and scale service personnel in developing an uncertainty statement that will accompany any reported values resulting from the calibration procedure. 


\section{Chapter 1}

\section{Background}

ISO/IEC 17025, "General Requirements of the Competence of Testing and Calibration Laboratories", states that a calibration or testing laboratory performing calibrations shall have, and shall apply, a procedure to estimate the uncertainty of measurement for all calibrations. It also requires that the customer be provided calibration reports that contain the measurement results and a statement regarding the measurement uncertainty. According to the definition of traceability, measurement results must be traceable to a national standard through an unbroken chain of calibrations or comparisons, each having a stated uncertainty.

Each value indicated by a scale or balance is an estimate of the true value of the material weighed. Each value also has a portion about which there is uncertainty, doubt, skepticism, suspicion or mistrust. This guide provides a practical method for calculating the uncertainty of a scale or balance calibration, in a manner useable by scale and balance service personnel who are not trained statisticians.

\section{History and development}

Over the years the NIST, Office of Weights and Measures (OWM), now designated as NIST Weights and Measures Division (WMD), has received many inquiries regarding the proper methods for calculating uncertainties of laboratory balances. More recently, due to industry requirements for uncertainty statements, NIST WMD has been receiving similar questions regarding uncertainties for scale calibrations. This comprehensive interpretive guide was developed to provide general guidance for the proper calculation of uncertainties for both scale and balance calibrations.

Complaints have been heard about how this "new" uncertainty requirement is being forced on the balance and scale service industry. However, the need for an understanding of uncertainty associated with measurements is not at all new. Research reveals that as early as 1960, U.S. Government requirements stated that the "collective uncertainty of the measurement standards shall not exceed 25 percent of the acceptable tolerance for each characteristic being tested". To ensure that this requirement was met, a rudimentary uncertainty analysis was required. Unfortunately, this was normally accomplished by evaluating only the allowable tolerances or uncertainties of the standards that were used in the calibration process, and did not include process-related uncertainty components such as repeatability and operator input. This typically resulted in an underestimation of the measurement uncertainty value.

Starting in the mid 1980's quality management system standards, in the form of the ISO/IEC 9000 series, were implemented as manufacturers tried to identify the causes of quality problems in their products and as competition on the international market intensified. The ISO/IEC 9000 documents provided a standardized methodology for dealing with all facets of a quality system through documentation of processes. Traceability of measurement results was one of the requirements set forth, with the quality of a measurement result directly relating to the traceability. In turn, traceability of measurement results requires documented evidence of the chain of preceding measurement results, and their associated uncertainties, to national standards. During that time, the impact of the process uncertainty on measurement results also became a topic of discussion, culminating in the 1993 publication of the ISO 


\section{Chapter 1}

Guide to the Expression of Uncertainty in Measurement (GUM). The GUM addresses the issue of uncertainty by looking at the complete measurement process. This includes the effect of the uncertainty of the calibration standards, as well as the impact of the processes involved in making the measurement and an engineering evaluation of data. This was not a totally new concept, for some organizations had been including variability of measurement in their uncertainty statements. But with the adoption of the GUM, the inclusion of process variability in uncertainty calculations became a widespread practice.

In 1995, the U.S. Government requirements expressed in MIL-STD-45662A were superseded by adoption of ISO/IEC Guide 25, General Requirements for the Competence of Calibration and Testing Laboratories, as ANSI/NCSL Z 540-1-1994, Part 1, which became the U.S. industry guideline. Laboratories fully compliant with ISO/IEC Guide 25 could be confident that their measurement results would be accepted by ISO/IEC 9000 compliant organizations because Guide 25 was written to address the requirements of ISO/IEC 9000 as they applied to calibration and testing laboratories. ISO/IEC Guide 25 required that measurement results be traceable to national standards, with measured values and reported uncertainties. At approximately the same time, ISO/IEC 9000: 1994 was issued and became the accepted quality management criteria of much of the manufacturing marketplace. ISO/IEC 9000 criteria, dealing primarily with manufacturing process and customer service issues, did not address the technical needs of the laboratories, but contained wording that required that calibration support be provided by ISO/IEC Guide 25 compliant laboratories.

In 1999, ISO/IEC 17025 replaced ISO/IEC Guide 25 as the requirements document for calibration and testing laboratories, and since has been adopted as the new U.S. industry standard. The traceability requirements remain virtually unaltered. Measurement results must be traceable to national standards through an unbroken chain of measurement results, with documented uncertainties. ANSI/NCSL Z 540-1-1994 was also reaffirmed in 2001 and is still in service. However, ISO/IEC 17025 takes precedence over ANSI/NCSL Z 540-12001 for accreditation bodies.

Inside the front cover of the GUM is this statement: "This Guide establishes general rules for evaluating and expressing uncertainty in measurement that are intended to be applicable to a broad spectrum of measurements." The GUM describes the general process that should be followed to calculate and document the uncertainty of measurement results. The writers of the GUM used partial derivatives and other mathematical processes requiring an extensive statistical background for proper implementation. In general, scale service personnel are unable to easily interpret and understand the GUM. (This is evidenced by the numerous inquiries received by WMD.)

As a result, numerous interpretive documents have been generated to address the calculation of uncertainties associated with specific calibration processes. Yet none have addressed one of the most fundamental and common measurement processes, the calibration of scales and balances. Scales and balances are used extensively in commerce and in analytical processes. Virtually everything bought or sold has a scale or balance somewhere in the process. Too often, the stated uncertainty of a scale or balance calibration has reflected only the tolerance 


\section{Chapter 1}

or uncertainty of the calibrating mass standards, which is an extremely minor component of the overall measurement uncertainty.

As stated above, compliance with ISO/IEC 17025 requires that an uncertainty estimation process, based on the GUM, be part of the daily operations of service organizations. Since few service organizations employ statisticians, NIST WMD has received a steadily increasing number of calls requesting assistance in establishing uncertainty statements for scale and balance system calibrations.

This Recommended Guide for Determining and Reporting Uncertainties for Balances and Scales has been developed to provide scale and balance service organizations with a practical interpretation of the GUM as it relates to the processes and measurement influences routinely encountered by their service personnel. 
Chapter 1

Printed: 11/29/02 8:28:00 AM 
Chapter 2

\section{Chapter 2: General concepts}




\section{Chapter 2}

\section{Introduction}

The calibration of a scale or balance consists of applying known loads to the device in a specified order, expecting the indicator to correctly indicate the weight of the applied load. The purpose of a balance or scale calibration is to measure the ability of the scale or balance to perfectly indicate the weight of the applied load under all conditions. The purpose is not to measure the weight of the applied standard mass artifacts. But no matter how perfectly the balance or scale indications appear to be, there will always be an uncertainty, or unknown quantity, associated with the calibration. The technician must assign a value to that unknown quantity for each measurement.

To be able to assign that value, the technician must have a good understanding of the equipment and the measurement process being used. This will allow him to take into consideration all of the factors that contribute to the uncertainty of the calibration. For instance, a scale indicator that has the zero tracking function turned 'on' may cause an indication error if a small load is applied to the weighing pan in a very slow manner. The indicator may interpret some initial portion of the applied weight as scale drift and zero the indication. This causes an erroneous shift in the zero reference and translates into an equal shift at all subsequently applied loads. If a technician is not completely familiar with the scale indicator, he may interpret that shift as an indication error when it is actually improper use of the weighing device. The impact of the zero tracking function on measurement results depends on a number of parameters that the manufacturer deems significant. The technician must be aware of potential error sources and the proper method for eliminating as many as possible.

There are many possible sources of uncertainty in a balance or scale calibration. Among the most common uncertainty contributors are:

- The uncertainty or tolerance of the applied load,

- repeatability of the weighing system,

- readability,

- reproducibility of the weighing system, and

- the effects of:

- temperature changes,

- drafts or wind,

- off center loading,

- indicator drift,

- electrical noise and variation

- vibration, and

Please note: This list is not all inclusive.

The balance or scale calibration technician must be capable of identifying those measurement influences that affect the measurement result and be able to estimate how each influence affects the balance or scale indication. These estimated quantities are then combined according to a documented procedure and reported as the uncertainty of the balance or scale calibration process. Randomly deciding to include or not include measurement influences in 


\section{Chapter 2}

uncertainty calculations does not comply with requirements in ISO/IEC 17025. Service providers must have a documented procedure that includes guidance on how decisions are to be made as to what is significant and must be included as part of the uncertainty. This may even include a requirement to describe in writing how the decisions are made at the time of each calibration.

The Guide to the Expression of Uncertainty in Measurement (GUM) describes a method for determining the uncertainty of a calibration.

\section{General Description of Method}

There are eight basic steps in the process of determining the uncertainty of a calibration. They are:

1. Specify the Process and equation:

Write down a clear, concise statement of what is being measured and the relationship between it and the parameters on which it depends. It must be remembered that the weighing device calibration process measures the ability of the weighing device to properly represent the applied calibration load. It is not measuring the mass of the applied load. A possible equation statement would be: $y=(m x+b) \pm U$

where $\quad \mathrm{y}$ is the balance indication,

$\mathrm{m}$ is the sensitivity of the weighing device,

$\mathrm{x}$ is the applied load,

$\mathrm{b}$ is the zero offset, and

$\mathrm{U}$ is the assigned measurement uncertainty.

\section{Identify and characterize the uncertainty sources}

Use a Cause and Effect diagram or uncertainty budget to help identify uncertainty contributors. The diagram or budget provides a systematic approach for listing all of the measurement influence factors that can cause an error in the balance or scale indication.

\section{Quantify the resulting uncertainty components}

Looking at the list of error contributors, assign a value to each, remembering that not all of them will be measured in mass units. For example, a change in temperature is measured in degrees Celsius or Fahrenheit and must be converted to mass units in the next step.

4. Convert the influences of the uncertainty components on the measurement to standard deviation equivalents

Using the example of temperature identified in step 3, convert that change in temperature to mass units. It may be necessary to consult the scale manufacturer's specifications to make conversions. All of the final values must be in terms of mass units.

Another factor that may require estimation is the standard deviation of the weighing system (the repeatability of the device). If the process of making repeated measurements to calculate a standard deviation of the scale indication is not practical, cost-effective or feasible, as may be the case for a large capacity scale, the standard 


\section{Chapter 2}

deviation may be approximated by using a portion of either the vendor's specification or the device readability, whichever is greater. This process is covered in detail in chapters 3,4 and 5 .

\section{Calculate the combined standard uncertainty $\left(u_{c}\right)$}

Use the root-sum-squared (RSS) method to combine the standard (one standard deviation) uncertainty components into a combined uncertainty value.

$u_{c}=\sqrt{s_{p}{ }^{2}+u_{1}^{2}+u_{2}{ }^{2}+u_{3}{ }^{2}+u_{4}{ }^{2}+u_{5}{ }^{2}+\ldots \ldots+u_{i}^{2}}$

where $s_{\mathrm{p}}$ is the process standard deviation and the terms containing ' $\mathrm{u}$ ' are other standard uncertainties.

\section{Calculate the expanded uncertainty (U)}

Multiply the combined standard uncertainty by the appropriate coverage factor for the confidence interval desired for the expanded uncertainty. Normally, $\mathrm{k}=2$ for a $95 \%$ confidence interval, will be used as the coverage factor. The use of other coverage factors requires that the selection and use be documented and justified when reported.

\section{Evaluate $\mathbf{U}$ for appropriateness}

Ask the following questions:

Does the expanded uncertainty make sense?

Is the expanded uncertainty at least two (or ' $\mathrm{k}$ ', if some other coverage factor was used) times the largest standard uncertainty component?

Is the expanded uncertainty large enough to encompass the normal indication errors that experience tells you are possible? If so, continue to step 8 . If not, investigate the calculations for mathematical errors or go back to step 2 and re-evaluate the calibration process looking for other causes of uncertainty that must be included.

\section{Report the uncertainty}

Report the expanded uncertainty value including the ' $\mathrm{k}$ ' factor used. NIST has adopted $\mathrm{k}=2$ as the standard value to be used in reporting the uncertainty of measurement results reported in the United States. If another $\mathrm{k}$ value is used, such as $\mathrm{k}=3$ for a $99.73 \%$ confidence interval, the use of the nonstandard $\mathrm{k}$ factor must be justified.

Additionally, a statement of traceability that includes a description of how the measurement and its associated uncertainty are traceable to a national metrological institute (NMI), such as NIST, should be included.

Each of these steps is expanded and explained as appropriate for the process being discussed in the examples in chapters 3,4 and 5. Examples of each common uncertainty contributor are provided along with discussion that will enable the user to categorize each uncertainty contributor.

\section{Application}

This guide provides the necessary tools to evaluate the calibration process being used, identify uncertainty contributors for the measurements made, quantify the impact of the uncertainty contributors on the measurement results, combine the uncertainty contributions in 


\section{Chapter 2}

a standardized manner, obtain and evaluate an expanded uncertainty, and report the measurement results with a properly computed, properly documented, uncertainty statement.

Chapters 3, 4 and 5 address specific processes. Each chapter addresses some special issues that are typically encountered in those calibration processes. Instructions are provided for the most appropriate method of calculating a reasonable uncertainty for a weighing device in each situation.

Chapter 6 contains sample calculations and includes the rationale that might be used in calculating and evaluating the resulting uncertainties. 


\section{Chapter 2}

Printed: 11/29/02 8:28:00 AM 
Chapter 3:

Balance Calibrations in a Laboratory Environment

\section{Chapter 3: \\ Balance Calibrations in a Laboratory Environment}




\section{Chapter 3: \\ Balance Calibrations in a Laboratory Environment}

\section{Introduction}

Laboratory balances are typically located in a controlled environment that minimizes many of the measurement influence factors that contribute to measurement uncertainty. Additionally, it is possible to perform repeated measurements due to the relatively small capacity of these weighing devices and the availability of suitable standards for all applied loads. The controlled environment and the ability to make repeated measurements simplify the process of calculating the calibration uncertainty. Therefore, service personnel must make fewer subjective decisions.

The following steps outline the process recommended for use by balance service personnel to calculate the uncertainty associated with the balance calibration process.

\section{Specify the Process and Equation}

Write down a clear concise statement of what is being measured and the relationship between it and the parameters on which it depends. Remember, the balance indication is being tested, not the mass of the standard mass artifacts.

Example: $y=(m x+b) \pm U$ where;

$\mathrm{y}$ is the balance indication, $\mathrm{m}$ is the sensitivity of the weighing device, $\mathrm{x}$ is the applied load, $\mathrm{b}$ is the zero offset, and $\mathrm{U}$ is the assigned measurement uncertainty.

Ideally, $\mathrm{b}=0$ if the balance indication was properly zeroed, and $\mathrm{m}=1$ because the balance indicates one mass unit for each mass unit applied.

\section{2,3 \& 4. Uncertainty Identification, Characterization and Quantification}

The uncertainty associated with the calibration of a laboratory balance is comprised of many influence factors. A cause and effect diagram is used here to identify the measurement influence factors and to show their relationship to other factors. 


\section{Chapter 3: \\ Balance Calibrations in a Laboratory Environment}

\section{Sample Cause and Effect Diagram}

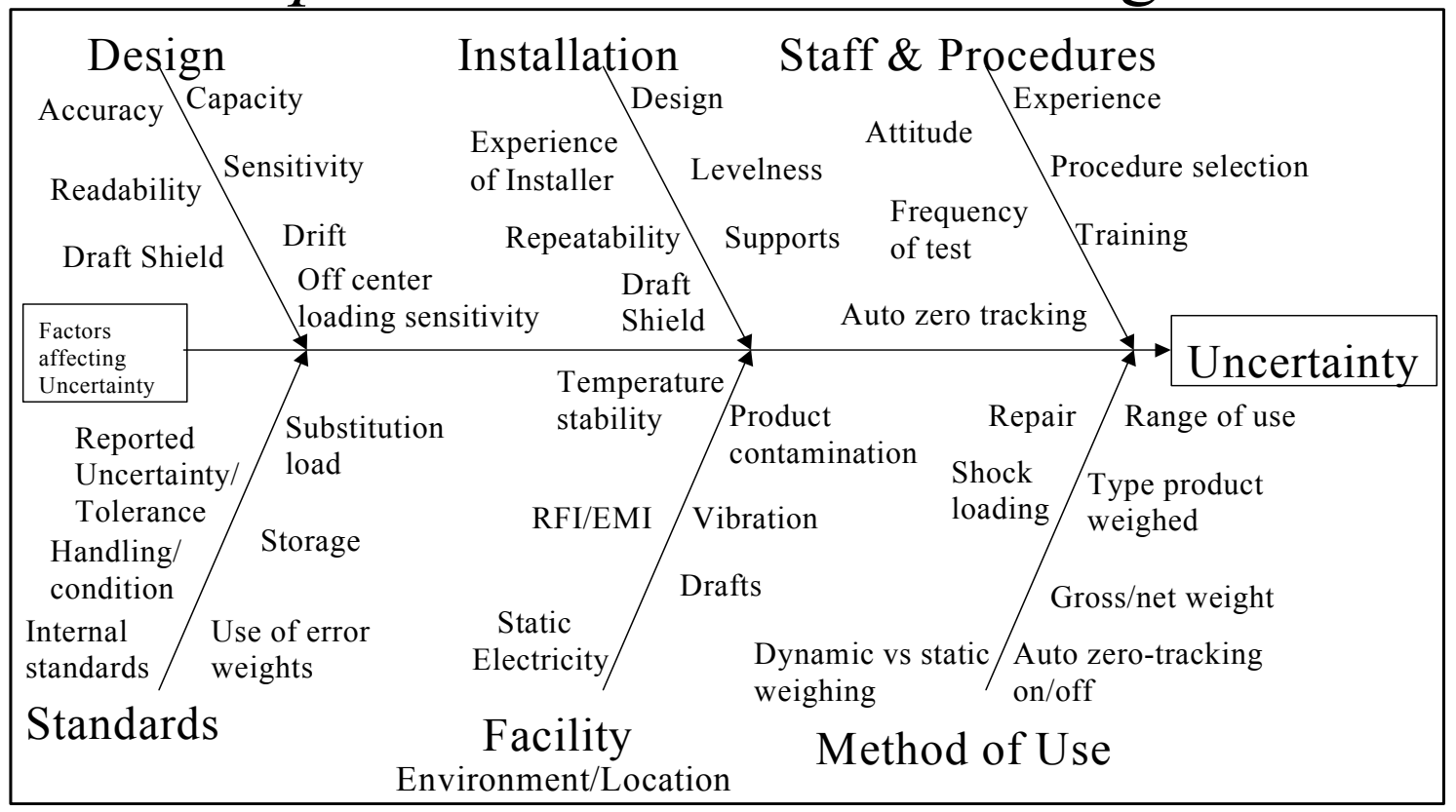

* Not all inclusive

In addition to the influences shown on the diagram, other sources of uncertainty may include magnetism of weights, standard mass errors, thermal equilibration of standards, balance warm-up, power-line noise, etc.

Evaluate each measurement influence for its significance. Consider an uncertainty component significant if it can cause a change in the value of the second most significant digit, leading zeros excluded, when included in the uncertainty calculations. For example, if the expanded uncertainty value is currently $0.052 \mathrm{~g}$ and including the value of an uncertainty contributor causes the new value to be $0.053 \mathrm{~g}$, that contributor is considered significant. If no change results in the second significant digit, the ' 2 ', the contributor is not considered significant for that particular calibration. When an uncertainty contributor is considered significant, a value for that uncertainty component must be included in the uncertainty calculations for that calibration process. Whether included in the uncertainty calculations or not, the GUM requires that the process of performing the evaluation, and the results of the evaluation, be documented for each known uncertainty contributor.

Many of the influence factors contained in the Sample Cause and Effect Diagram are addressed in the following paragraphs. The individual(s) performing the test must decide how to deal with each influence, whether by avoidance, correction or inclusion as part of the uncertainty.

The service staff must evaluate the environment and use of the balance and eliminate or minimize as many of the measurement influence factors as possible. Engineering changes put in place to minimize a measurement influence must remain in place at all times for the calibration uncertainty to remain valid. 


\section{Chapter 3: \\ Balance Calibrations in a Laboratory Environment}

Levelness of the balance should be checked and corrected if necessary.

Drafts should be eliminated by the installation of draft shields, air diffusers or by redirecting air vents, or closing doors. These draft elimination measures must be in place at all times (including during use) for the calibration uncertainty statement to remain valid during daily use.

Off-center loading errors should be evaluated and corrected before recording final calibration data.

Thermal equilibrium of the balance should be ensured by maintaining the balance in an energized state (i.e., turned-on) for sufficient time to ensure that all circuitry and hardware have reached a stable temperature.

Vibration sources must be identified and eliminated or minimized to limit the vibration levels to which the weighing device is exposed during daily use, as well as during calibration.

Zero-tracking features should be disabled to avoid undetectable zero indication errors. Zero-tracking is designed to eliminate minor changes in the balance indication due to drift of the weighing system and may be turned 'on' to maintain the 'zero' indication of the weighing device. Due to the correction limits included in the system programming regarding quantity and motion detection, detrimental effects on measurement results are typically not evident. However, service personnel may encounter times while attempting to load the pan that the zero tracking circuitry will cause an offset in the indication, particularly if placing weights in a very slow, gentle manner. While this would be an unusual occurrence, service personnel must be aware of the possibility of such errors and take steps to prevent them from occurring.

Mass Standards must be brought into close proximity to the balance, even installed inside the balance chamber where possible, to ensure thermal equilibrium with the balance and surrounding environment prior to calibration. This becomes more critical for balances and weights of higher or improved accuracy. Table B.2 of the 2002 Draft of OIML R 111, the OIML specification for weights, recommends that weights be permitted to undergo thermal stabilization for as long as 79 hours, depending on the desired use, nominal mass, weight accuracy class and temperature differential. 


\section{Chapter 3: \\ Balance Calibrations in a Laboratory Environment}

Excerpt from Table B.2*

Thermal stabilization in hours

\begin{tabular}{|l|c|c|c|c|c|}
\hline$\Delta \boldsymbol{T}^{*}$ & Nominal Value & Class E $_{\mathbf{1}}$ & Class $_{\mathbf{2}}$ & Class $_{\mathbf{1}}$ & Class $_{\mathbf{2}}$ \\
\hline \multirow{5}{*}{ $\pm 20^{\circ} \mathrm{C}$} & $1000,2000,5000 \mathrm{~kg}$ & - & - & 79 & 5 \\
\cline { 2 - 6 } & $100,200,500 \mathrm{~kg}$ & - & 70 & 33 & 4 \\
\cline { 2 - 6 } & $10,20,50 \mathrm{~kg}$ & 45 & 27 & 12 & 3 \\
\cline { 2 - 6 } & $1,2,5 \mathrm{~kg}$ & 18 & 12 & 6 & 2 \\
\cline { 2 - 6 } & $100,200,500 \mathrm{~g}$ & 8 & 5 & 3 & 1 \\
\cline { 2 - 6 } & $10,20,50 \mathrm{~g}$ & 2 & 2 & 1 & 0.5 \\
\cline { 2 - 6 } & $<10 \mathrm{~g}$ & 1 & 1 & 1 & 0.5 \\
\hline
\end{tabular}

Failure to allow the weights to sufficiently stabilize prior to beginning balance calibrations can cause significant errors in the measurement of the applied mass. This is because thermal air currents are generated around the balance weighing pan due to the temperature variations within the measuring system. Only adequate thermal stabilization times will prevent this phenomenon from occurring. The service personnel should apply stabilization considerations similar to those in OIML R 111 when calibrating balances requiring the use of OIML Class $\mathrm{E}_{2}, \mathrm{~F}_{1}, \mathrm{~F}_{2}$, and ASTM Class 1, 2 or 3 weights.

Standard mass errors can be minimized by using the mass values reported during calibration of the mass artifacts.

Balance indication drift errors should be corrected to the maximum extent possible. Though slight drift in the indicated value is somewhat normal, significant indication drift may be a sign of thermal instability of the weighing system. Allowing a longer temperature stabilization period for the weighing device and standard mass artifacts may minimize drift due to thermal instability. Exercising the weighing system may also act to minimize drift. Repeatedly applying and removing loads within the range of the device causes the electronic and mechanical components of the system to acquire a thermal equilibrium of use. If indication drift is excessive and cannot be eliminated by longer warm-up times or exercising the weighing system, other corrective action must be taken.

Magnetic fields surrounding weights or weight handling devices can cause severe, yet difficult to detect, errors in the indication generated by an applied mass load. Whenever possible, mass artifacts and handling devices made of non-magnetic materials should be used. When influences due to magnetic fields are suspected, measurements using different weight artifacts should be performed. Magnetic effects may be detected by making a series of mass measurements of the weight, half of the measurements with the weight in an upright position and half of the measurements with the weight inverted. Magnetism is probable if a detectable difference, greater than the repeatability of the balance, is noted between the average of the upright indications and the average of the inverted indications. If magnetism is suspected, weights should be tested more extensively for magnetic fields. A further description of the test for magnetism is 


\section{Chapter 3: \\ Balance Calibrations in a Laboratory Environment}

beyond the scope of this document. Use weights known to be non-magnetic for calibration of balances using the force balance principle.

RFI/EMI susceptibility tests should be performed. Changes in indication due to random RFI/EMI influences can be difficult to detect during normal use, and may be interpreted as repeatability errors, drift or erratic readings. Corrective action should be taken if RFI/EMI susceptibility is detected.

Note: RFI/EMI sources include two-way radios, cell phones and other electronic devices. Laboratories are available specializing in detecting and measuring RFI/EMI.

Power-line noise or variations can cause random display indications to occur. The specific cause of these random indications may be difficult to determine, but they will affect the repeatability of the weighing system. Where possible, it is best that balances be powered by a dedicated power circuit or by an AC line conditioner to prevent these measurement influences.

Operator errors result when individuals are inadequately trained. All operators of weighing devices should have proper training and be knowledgeable about the weighing instrument and the process in which it is used. Inadequately trained personnel may record data with significant errors, improperly influencing critical process decisions. Weighing system operators must be equipped with correct and complete work instructions to minimize the likelihood of operator error.

Careful planning or suitable corrective action will minimize or eliminate many balance measurement uncertainty sources. However, there are several uncertainty influences that cannot be eliminated. The results of these influences must be included in the calibration uncertainty calculations. Each are discussed in the following paragraphs.

\section{Process standard deviation $\left(s_{\mathbf{p}}\right)$}

The source of a value for $s_{p}$ can be based on balance repeatability, balance reproducibility or the size of a balance division. Each method is discussed below.

\section{$s_{p}$ from measured repeatability}

Repeatability is a measure of a balance's ability to produce the same indication every time the same weight is placed on the sensing device. Repeatability is presented as a standard deviation. Obtaining repeated measurement results is possible in the laboratory due to the small size and ready availability of the weights used. Repeatability tests should be conducted with weights approximating the typically measured load. If a wide range of load values are normally measured, evaluation of repeatability at several loads, e.g., $50 \%$ capacity and $100 \%$ capacity, may be desirable. If the repeatability value at one load is more than two times the value at a second load, it may be desirable to report the repeatability results at specific load ranges of the balance. If only a single repeatability value is to be reported, the largest measured value must be used.

Seven or more measurement results of a weight are required to calculate the repeatability or standard deviation of the balance at a given load. Increasing the number of measurement results provides greater confidence in the value. The calculated standard 


\section{Chapter 3: \\ Balance Calibrations in a Laboratory Environment}

deviation obtained in this manner is a measure of the weighing system's ability to repeat measurement results over a short time interval and does not represent the long-term reproducibility.

Due to balance resolution, it is possible to make seven or more measurements with every measurement resulting in the same value. A true balance standard deviation of zero is not statistically possible, though the standard deviation may be less than one display increment (d). In this situation, assuming that a control chart of a check standard is not available, the standard deviation of the balance can be estimated as $s_{p}=\frac{d}{\sqrt{3}}=0.577 d$ ( 0.577 times the value of ' $d$ ') as described in the GUM. This method of calculating the $\mathrm{s}_{\mathrm{p}}$ value is recommended only if the result of a series of repeatability weighings is zero.

If it is possible to perform a discrimination test as described in NIST Handbook 44, N.1.5 and T.N.7.1 or OIML R 76-1, A.4.8, another equation may be used. The equation $s_{p}=\frac{1}{2} \frac{d}{\sqrt{3}}=0.29 d$ ( 0.29 times the value of ' $\mathrm{d}$ ') can be used as it has been proven that the true value is statistically most probable to lie near the center of the scale display interval. This estimation equation should only be used when the calculated standard deviation is zero and the balance has passed a discrimination test as described in NIST Handbook 44, N.1.5 and T.N.7.1 or OIML E 76-1, A.4.8.

\section{$s_{p}$ from measured reproducibility}

When the uncertainty of the balance during routine weighing operations is desired, a check standard and control chart should be used to determine the long-term repeatability of the balance under varying operational conditions. This is called reproducibility and is also evaluated as a standard deviation. Reproducibility is a measure of long-term repeatability and may be used in place of the short-term repeatability when calculating measurement uncertainty. The standard deviation value of the control chart will be included in the combined uncertainty as $\mathrm{s}_{\mathrm{p}}$. The load chosen for use as the check standard should represent the items typically weighed on the balance.

When using values from control charts to determine the $s_{p}$ value, attention must be given to the range of measurement results over which that value has been determined. When readings from a wide range of measurement results are included in the calculation of the $\mathrm{s}_{\mathrm{p}}$ value and the resulting standard deviation is acceptable, an uncertainty calculated from that standard deviation is valid for the range over which the measurement results were obtained. However, it is possible that the calculated uncertainty is greater than desired or greater than is acceptable. Repair of the weighing device may not correct the problem. For those situations, it may be desirable to divide the data into measuring ranges and to calculate the standard deviation of each of several narrower measuring ranges. These standard deviations are applicable to the measuring range over which the data was obtained. Especially in a calibration facility, a balance may have multiple $s_{p}$ values each covering a different range of the balance capacity. The existence of multiple $s_{p}$ values requires the calculation of expanded uncertainty values for each assigned measuring range. 


\title{
Chapter 3: \\ Balance Calibrations in a Laboratory Environment
}

\begin{abstract}
$s_{p}$ from manufacturer's specification
The value for $s_{p}$ is best determined from repeated readings of a weight, whether shortterm or long-term. The manufacturer's specification sheet is not a recommended source for determining the uncertainty contribution due to repeatability. Manufacturers' specifications are established for a specific set of conditions that may not be representative of the actual environment in which the scale is tested and used. Manufacturers' specifications are an excellent tool when comparing the expected performance of one weighing device to another similar device, but they are established to indicate the expected performance of a family of weighing systems, not a specific weighing system. As the calibration uncertainty is being estimated for a specific weighing system, it is best to establish the calibration uncertainty contribution due to repeatability from measured data, not from an expected performance parameter. Manufacturers' specifications should not be used to estimate calibration uncertainty.
\end{abstract}

\section{Uncertainty of the standards $\left(u_{s}\right)$}

The uncertainty associated with the standard mass artifacts, $u_{s}$, may come from one of several possible sources. $u_{\mathrm{s}}$ may be based on the calibration uncertainty assigned to the calibrated value of the standard mass artifact as taken from the calibration report, or it may be based on the tolerance to which the standard mass has been verified. A calibration load may include one mass artifact or multiple mass artifacts. Each of these situations requires a different method for determining the proper way to calculate the $u_{s}$ value.

\section{$u_{s}$ from mass artifact calibration uncertainty}

When using the reported calibration value of the standard mass artifact in the calibration of the balance, calculate the uncertainty of the mass standard $\left(u_{s}\right)$ from the uncertainty associated with the reported values of the individual mass artifact. Normally, standard mass uncertainties are reported as expanded uncertainties with a stated coverage factor (k). Divide the expanded uncertainty of the standard mass artifacts by the reported coverage factor $(\mathrm{k})$ to obtain the standard uncertainty for the mass artifact.

\section{$u_{s}$ from mass artifact calibration tolerance}

When basing the standard mass uncertainty $\left(\mathrm{u}_{\mathrm{s}}\right)$ on the tolerance of the standard mass artifact, treat the tolerance as having a uniform probability distribution. The standard mass uncertainty calculated from the standard mass calibration tolerance is

$$
u_{s}=\frac{\text { tolerance }}{\sqrt{3}}=0.577(\text { tolerance }) \text {. }
$$

\section{Dealing with Multiple standards: Additional Guidance}

When using multiple weights to generate a single load the most conservative value for the uncertainty of the mass calibrations $\left(\mathrm{u}_{\mathrm{s}}\right)$ is the linear sum of the standard uncertainty associated with each weight. For this situation $u_{s}=u_{s m 1}+u_{s m 2}+u_{s m 3}+\ldots . .+u_{s m i}$. While this method provides the most conservative estimate of standards uncertainty, it also typically provides the largest estimate for the standards uncertainty and may result in an uncertainty value that is greater than is allowed by the customer's weighing process. 


\section{Chapter 3: \\ Balance Calibrations in a Laboratory Environment}

A less conservative method, the root-sum-squared (RSS) method, results in a smaller estimated standard mass uncertainty value. The equation for the RSS method is $u_{s}=\sqrt{u_{s m 1}^{2}+u_{s m 2}^{2}+u_{s m 3}^{2}+\ldots \ldots+u_{s m i}^{2}}$. This method of combining the standard uncertainties of the mass standards requires that you prove independence between the reported value of each mass standard. Values are independent when no portion of the value of one weight affects the value of another. Obtain information about mass value independence from the calibrating organization. When the user is unsure of the independence of values, he must assume that the values are dependent and use the sum of the individual uncertainties for $u_{s}$.

\section{Calculating the combined uncertainty}

The combined uncertainty, ' $u_{\mathrm{c}}$ ', of the weighing system calibration is calculated as the rootsum-squared of the influence factors.

$u_{c}=\sqrt{u_{s}^{2}+s_{p}^{2}+u_{1}^{2}+u_{2}^{2}+u_{3}^{2}+\ldots .+u_{i}^{2}}$ where $\mathrm{u}_{\mathrm{i}}$ are any other uncertainty components that the scale technician includes in the uncertainty calculations.

\section{Remember:}

- All of the uncertainty components must be in like terms of the mass units. Differing units, such as ${ }^{\circ} \mathrm{C}$ and $\mathrm{mg}$, cannot be combined. Convert the impact of the non-mass units to appropriate mass units to calculate the uncertainty.

- All uncertainty components must be in terms of standard (one standard deviation) uncertainties.

\section{Calculating the expanded uncertainty}

The expanded uncertainty, ' $U$ ', is calculated by multiplying the value obtained for $\mathrm{u}_{\mathrm{c}}$ by the coverage factor, ' $\mathrm{k}$ ', for the confidence interval to be used. By convention, as defined in NIST Technical Note 1297, "Guidelines for Evaluating and Expressing the Uncertainty of NIST Measurement Results", a coverage factor of $\mathrm{k}=2$ is used for a confidence interval of approximately $95 \%$. The use of $\mathrm{k}$ values other than $\mathrm{k}=2$ requires an explanation of the reason for the deviation from convention.

\section{Evaluating the expanded uncertainty}

There are several things to consider when evaluating the uncertainty. First, does the final expanded uncertainty make sense? The expanded uncertainty must be at least ' $\mathrm{k}$ ' times greater than the largest uncertainty component included.

Second, does the calculated expanded uncertainty seem appropriate for the tested device? An uncertainty value seems unreasonable and should be investigated if the expanded uncertainty is calculated to be significantly less than one balance division. Likewise, if the calculated uncertainty is excessively large, that value should be investigated. Investigation should include verifying the use of proper evaluation techniques. Ensure that arithmetical errors were not the cause of the questionable uncertainty value.

Third, does the calculated uncertainty meet the requirements for weighing with that weighing device? Different quality systems have different requirements concerning the allowable measurement uncertainty; requirements may state that the uncertainty of a measuring device 


\section{Chapter 3: \\ Balance Calibrations in a Laboratory Environment}

may not exceed $33 \%, 25 \%$, or even as little as $10 \%$, of the tolerance of the object being tested. Will the calculated uncertainty meet the requirements that are in place? If not, reexamine the entire calibration process for uncertainty contributors that can be reduced. Reduction may be accomplished by selection of more accurate standards, repair of the weighing device to obtain a smaller standard deviation, or perhaps making multiple measurements to determine the true repeatability of a device rather than using an estimated repeatability. Evaluate each uncertainty contributor, beginning with the most significant, to determine how it can legitimately be reduced until the required uncertainty level is obtained or until the decision is made that the weighing device cannot meet the quality requirements and must be replaced or that the weighing system must be moved to a more hospitable environment.

Remember, the reported calibration uncertainty is valid only for the environment in which it is determined. Temporarily improving the environment for the calibration, then returning it to the prior conditions for normal weighing operations invalidates the uncertainty statement. Engineering changes made to reduce calibration uncertainty must remain in place during normal weighing operations for the calibration uncertainty to remain valid.

\section{Reporting Uncertainty}

Reporting the expanded uncertainty value is no longer a matter of simply stating that a measurement result is ' $x \pm y$ ' where ' $x$ ' is the reported value and ' $y$ ' is the expanded uncertainty. The Guide to the Expression of Uncertainty in Measurement requires that you identify the various components of the uncertainty. You must also explain why that component was included and how it was evaluated. Specifically, the GUM provides a test of the stated uncertainty statement: "Has enough information been provided in a sufficiently clear manner that the result can be updated in the future if new information or data became available?" Another test is to ask: "Would another individual, not associated with the measurement process, be able to understand how the stated uncertainty was calculated and what was included, and then properly apply it to his/her own uncertainty calculation?"

It must be understood that the measurement uncertainty must be calculated for each balance test load. The needs of the customer will determine whether a table format is used to report the uncertainty at each load, or the maximum uncertainty value of all test loads is reported as a single value covering the entire range of the weighing system. In either case, the uncertainty at each test load must be calculated and documented.

It is very important that uncertainty calculations be understandable so that the user can properly include the uncertainty components in their process uncertainty calculations. Some components of the uncertainty need to be addressed differently than other components, and sufficient information must be available to make that possible. For example, when calculating the uncertainty of his production process the customer would likely not wish to include reproducibility if the reproducibility value from a control chart of the measuring process was used to calculate the uncertainty of the balance calibration. To include the reproducibility value a second time would needlessly increase the expanded uncertainty of the production measurement process. Sufficient information must be provided to the user so 


\section{Chapter 3: \\ Balance Calibrations in a Laboratory Environment}

that it is clear that the reproducibility should be included only once, in the originally reported balance uncertainty.

The importance of a clear, understandable and defensible uncertainty statement, based on a properly documented set of instructions, cannot be emphasized too strongly. The uncertainty statement is a critical portion of the calibration process. Write the uncertainty statement so that a user can make informed decisions concerning proper use of the uncertainty components provided.

The following tables provide a quick reference guide to the proper equation to use for calculating the calibration uncertainty in most common situations. They also provide an example of a form that might be used to document the calibration uncertainty. 
Chapter 3:

Balance Calibrations in a Laboratory Environment 


\section{Chapter 3:}

Balance Calibrations in a Laboratory Environment

\section{Quick Guide for Laboratory Balance Calibration Uncertainties}

Reference information:

\begin{tabular}{|l|l|c|c|}
\hline \multicolumn{2}{|c|}{ Process $\left(\mathbf{s}_{\mathbf{p}}\right)$ Source (in order of desirability): } & $\begin{array}{c}\text { Distribution } \\
\text { Type }\end{array}$ & $\begin{array}{c}\text { Value to } \\
\text { use: }\end{array}$ \\
\hline 1 & $\begin{array}{l}\text { Calculated standard deviation at the test load from an up- } \\
\text { to-date control chart }\end{array}$ & Normal & As calculated \\
\hline 2 & $\begin{array}{l}\text { Calculated standard deviation from 10 or more readings of } \\
\text { the same load over a short period of time }\end{array}$ & Normal & As calculated \\
\hline
\end{tabular}

\begin{tabular}{|l|l|c|c|}
\hline \multicolumn{2}{|l|}{$\begin{array}{l}\text { Standards ( } \\
\text { (in order of desirability): }\end{array}$} & $\begin{array}{c}\text { Distribution } \\
\text { Type }\end{array}$ & $\begin{array}{c}\text { Value to } \\
\text { use: }\end{array}$ \\
\hline 1 & Reported k=1 uncertainty from Report of Test & Normal & As calculated \\
\hline 2 & Tolerance of weight(s) used & Uniform & $\begin{array}{c}0.577 \mathrm{x} \\
\text { tolerance }\end{array}$ \\
\hline Additional equations when using multiple standards & \multicolumn{2}{|l}{} \\
\hline A & Multiple standard masses (if independence is proven) & $u_{s}=\sqrt{u_{s m 1}^{2}+u_{s m 2}^{2}+u_{s m 3}^{2}+\ldots . .+u_{s m i}^{2}}$ \\
\hline B & Multiple standard masses (if independence is unknown) & $u_{s}=u_{s m 1}+u_{s m 2}+u_{s m 3}+\ldots . .+u_{s m i}$. \\
\hline
\end{tabular}

Additionally, there may be other known measurement uncertainty contributors. Evaluate the calibration process carefully to ensure that all significant contributors are properly included in the uncertainty calculations. Consult the text of this Guide for additional guidance. 


\section{Chapter 3:}

Balance Calibrations in a Laboratory Environment

\section{Equipment Identification}

\begin{tabular}{|l|l|l|l|l|}
\hline Manufacturer & Model & Serial & ECN & Other \\
\hline & & & & \\
& & & & \\
\hline
\end{tabular}

\section{Uncertainty Worksheet}

at Test Load

\begin{tabular}{|l|c|c|c|c|}
\hline Uncertainty Influence Description & Identifier & $\begin{array}{c}\text { Estimated } \\
\text { value }\end{array}$ & $\begin{array}{c}\text { Distribution } \\
\text { type } \\
\text { (Normal/Uniform) }\end{array}$ & $\begin{array}{c}\text { Estimated } \\
\text { Standard } \\
\text { Uncertainty }\end{array}$ \\
\hline Uncertainty of the standards used & $\mathrm{u}_{\mathrm{s}}$ & & & \\
\hline $\begin{array}{l}\text { Standard deviation of the process } \\
\text { (Determined at coad) }\end{array}$ & $\mathrm{s}_{\mathrm{p}}$ & & & \\
\hline Uncertainty due to & $\mathrm{u}_{1}$ & & & \\
\hline Uncertainty due to & $\mathrm{u}_{2}$ & & & \\
\hline Uncertainty due to & $\mathrm{u}_{3}$ & & & \\
\hline Uncertainty due to & $\mathrm{u}_{4}$ & & & \\
\hline Uncertainty due to & $\mathrm{u}_{5}$ & & & \\
\hline Uncertainty due to & $\mathrm{u}_{6}$ & & & \\
\hline Uncertainty due to & $\mathrm{u}_{6}$ & & & \\
\hline Uncertainty due to & & & \\
\hline
\end{tabular}

\section{Combined standard uncertainty}

$$
u_{c}=\sqrt{u_{s}^{2}+s_{p}^{2}+u_{1}^{2}+u_{2}^{2}+u_{3}^{2}+u_{4}^{2}+u_{5}^{2}+\ldots .+u_{i}^{2}} \quad \mathrm{u}_{\mathrm{c}}=
$$

\section{Expanded uncertainty \\ $\mathrm{U}=\mathrm{k}\left(\mathrm{u}_{\mathrm{c}}\right), \mathrm{k}=$}

$\mathrm{k}=2$ is recommended

$\mathrm{U}=$ 


\section{Chapter 4:}

\section{Chapter 4: Scale Calibrations Performed in an Uncontrolled Environment}

(E.g., a truck scale in a quarry or steel mill) 


\section{Chapter 4: \\ Scale Calibrations Performed in an Uncontrolled Environment}

\section{Introduction}

This chapter identifies many of the measurement influences affecting scale calibrations in an uncontrolled environment and provides instructions on how to include the resulting uncertainty contributors in a calculated expanded uncertainty for the calibration. It is not possible to discuss all possible measurement influences, but the examples will provide adequate guidance to enable the service personnel to make informed decisions when calculating calibration uncertainty.

\section{Scales in an uncontrolled environment}

Large capacity scales, such as truck scales or floor scales, are often installed out-of-doors in an uncontrolled environment. Thus, many influences affect the calibration uncertainty. Many of these influences are beyond the ability of service personnel to control, so they must be identified and evaluated for the impact they have on the calibration process.

The following steps outline the process recommended for use by scale service personnel to calculate the uncertainty associated with the scale calibration process.

\section{Specify the Process and Equation}

Write down a clear concise statement of what is being measured and the relationship between it and the parameters on which it depends. Remember, the scale indication is being tested, not the mass of the standard mass artifacts.

Example: $y=(m x+b) \pm U$ where;

$\mathrm{y}$ is the scale indication, $\mathrm{m}$ is the sensitivity of the weighing device, $\mathrm{x}$ is the applied load, $\mathrm{b}$ is the zero offset, and $\mathrm{U}$ is the assigned measurement uncertainty.

Ideally, $\mathrm{b}=0$ if the scale indication was properly zeroed, and $\mathrm{m}=1$ because the scale indicates one mass unit for each mass unit applied.

\section{2, 3 \& 4. Uncertainty Identification, Characterization and Quantification}

The uncertainty associated with the calibration of a laboratory balance is comprised of many influence factors. A cause and effect diagram is used here to identify the measurement influence factors and to show their relationship to other factors. 


\section{Chapter 4:}

\section{Scale Calibrations Performed in an Uncontrolled Environment}

\section{Sample Cause and Effect Diagram}

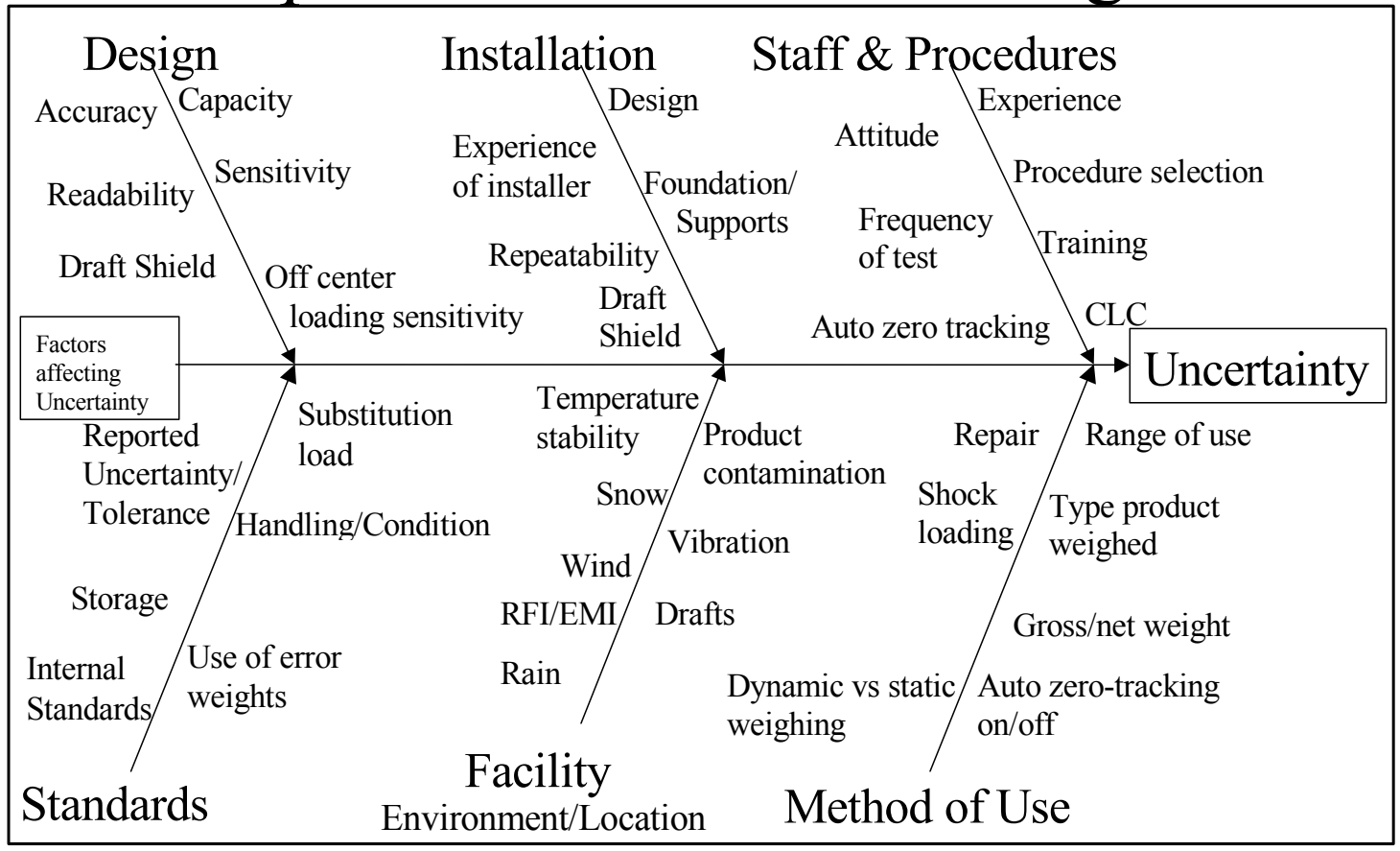

* Not all inclusive

In addition to the influences shown on the diagram, other possible causes of uncertainty are standard mass errors, thermal equilibration of standards, scale warm-up, power-line noise, etc.

Evaluate each uncertainty influence for its significance. Consider an uncertainty component significant if it can cause a change in the value of the second most significant digit, leading zeros excluded, when included in the uncertainty calculations. For example, if the expanded uncertainty value is currently $0.52 \mathrm{~kg}$ and including the value of an uncertainty contributor causes the new value to be $0.53 \mathrm{~kg}$, that contributor is considered significant. If no change results in the second significant digit, the ' 2 ', the contributor is not considered significant for that particular calibration. When an uncertainty contributor is considered significant, a value for that uncertainty component must be included in the uncertainty calculations for that calibration process. Whether included in the uncertainty calculations or not, the GUM requires that the process of performing the evaluation, and the results of the evaluation, be documented for each known uncertainty contributor.

Many of the influence factors contained in the Sample Cause and Effect Diagram are addressed in the following paragraphs. The individual(s) performing the test must decide how to deal with each influence, whether by avoidance, correction or inclusion as part of the uncertainty.

The service staff must evaluate the environment and use of the scale and eliminate or minimize as many of the measurement influence factors as possible. Engineering changes 


\section{Chapter 4:}

\section{Scale Calibrations Performed in an Uncontrolled Environment}

put in place to minimize a measurement influence must remain in place at all times for the calibration uncertainty to remain valid.

Levelness of the scale should be checked and corrected if necessary.

Wind influences are typically very difficult and expensive to eliminate for large scales in an uncontrolled environment. However, any controls in place for the calibration must remain in place for all weighing operations. Guidance for including an uncertainty component for wind influences is provided later in this chapter.

Off-center loading errors should be evaluated and corrected before recording final calibration data.

Thermal equilibrium of the scale should be ensured by keeping the scale in an energized state (i.e., turned-on) for sufficient time to ensure that all circuitry and hardware have reached a stable temperature.

Vibration sources must be identified and eliminated or minimized to limit the vibration levels to which the weighing device is exposed during daily use, as well as during calibration.

Zero-tracking features should be disabled to avoid undetectable zero indication errors. Zero-tracking is designed to eliminate minor changes in the scale indication due to drift of the weighing system and may be turned 'on' to maintain the 'zero' indication of the weighing device. Due to the correction limits included in the system programming regarding quantity and motion detection, detrimental effects on measurement results are typically not evident. However, service personnel attempting to load the load receiver may at times find that the zero tracking circuitry will cause an offset in the indication, particularly if placing weights in a very slow, gentle manner or when using a weight cart to load the scale. While this would be an unusual occurrence, service personnel must be aware of the possibility of such errors and take steps to prevent them from occurring.

Mass Standards must be brought into close proximity to the scale to ensure thermal equilibrium with the scale and surrounding environment. Thermal stabilization times for weights typically used for a scale in this environment are not specified, but sufficient time must be allowed to ensure that condensation is not present on the weights.

Mass standard error effects are minimized by using the mass values determined during calibration of the mass artifacts. For most large capacity scales this will not be necessary as the tolerances of the scales and standard masses have been set to minimize the effects of the standard mass errors. The concept is presented here as an option should correction be desirable. The standard mass uncertainty for large capacity scales is normally based on the tolerance of the mass standards.

However, if the mass corrections of the standard masses are used, the reported calibration uncertainty of the mass calibration must be used as $u_{s}$. The complete 


\section{Chapter 4: \\ Scale Calibrations Performed in an Uncontrolled Environment}

calculation of $\mathrm{u}_{\mathrm{s}}$ is covered in a later section of this chapter. Additionally, the length of re-calibration intervals and care and handling of weights directly affects the validity of the mass corrections determined at calibration. Mass corrections for weights that are abused or stored in harsh environments, such as on an open truck bed without benefit of cover, may no longer be valid. Thus, mass corrections must be used with discretion.

Scale indication drift errors should be corrected to the maximum extent possible. Though slight drift in the indicated value is somewhat normal, significant indication drift may be an indication of thermal instability of the weighing system. Allowing a longer temperature stabilization period for the weighing device and standard mass artifacts can minimize drift due to thermal instability. Exercising the weighing system may also minimize drift. Repeatedly applying and removing loads within the range of the device causes the electronic and mechanical components of the system to acquire a thermal equilibrium of use. If indication drift is excessive and cannot be eliminated by the means described, other corrective action must be taken.

RFI/EMI susceptibility tests should be performed. Changes in indication due to random RFI/EMI influences can be difficult to detect during normal use and may be interpreted as repeatability errors, drift or erratic readings. Corrective action should be taken if RFI/EMI susceptibility is detected.

Note: RFI/EMI sources include two-way radios, cell phones and other electronic devices. Laboratories are available specializing in detecting and measuring RFI/EMI.

Power-line noise or variations can cause random display indications to occur. The specific cause of these random indications may be difficult to determine, but they will affect the repeatability of the weighing system. Where possible, it is best that scales be powered by a dedicated power circuit or by an AC line conditioner to prevent these measurement influences.

Operator errors result when operators are inadequately trained. All operators of weighing devices should have proper training and be knowledgeable about the weighing instrument and the process in which it is used. Inadequately trained personnel may record data with significant errors, improperly influencing critical process decisions. Weighing system operators must be equipped with correct and complete work instructions to minimize the likelihood of operator error.

Careful planning or suitable corrective action will minimize or eliminate many scale measurement uncertainty sources. However, there are several uncertainty influences that cannot be eliminated. The results of these influences must be included in the calibration uncertainty calculations. Each are discussed in the following paragraphs.

\section{Process standard deviation $\left(s_{p}\right)$}

The source of a value for $s_{p}$ can be based on scale repeatability, scale reproducibility, the size of a scale division or a manufacturer's specification. Each are discussed below. 


\section{Chapter 4:}

\section{Scale Calibrations Performed in an Uncontrolled Environment}

\section{$s_{p}$ from measured repeatability}

Repeatability is a measure of a scale's ability to produce the same indication every time an identical load, under the same conditions, is placed on the sensing device.

Repeatability is presented as a standard deviation. The most desirable method for determining repeatability is to make a number of measurements at a load that is typical of routine weighing operations. At least seven measurement results of a repeated specific scale load are required to calculate the standard deviation of a scale. Typically, due to time, energy or cost constraints, service personnel do not perform repeatability testing of large capacity scales. Instead, a method for estimating the repeatability is required.

It is possible that when performing repeatability testing, due to scale resolution, the same value is obtained for every measurement resulting in a standard deviation of zero. A true scale standard deviation of zero is not statistically possible, though the standard deviation may be significantly less than one display increment (d). In this situation, if a control chart of a check standard is not available, the standard deviation of the scale can be estimated from the scale display resolution as described below.

\section{$S_{p}$ from display resolution}

The repeatability may be estimated from display resolution as $s_{p}=\frac{d}{\sqrt{3}}=0.577 d(0.577$ times the value of ' $d$ ') as described in the GUM. This equation assumes that no discrimination test, as described in NIST Handbook 44, N.1.5 and T.N.7.1 or OIML R 76-1, A.4.8, has been performed to evaluate the scale response to scale load changes smaller than one scale division.

If it is possible to perform a discrimination test, a slightly different equation may be used. That equation is: $s_{p}=\frac{1}{2} \frac{d}{\sqrt{3}}=0.29 d$ ( 0.29 times the value of ' $\mathrm{d}$ ') since passing a discrimination test indicates that the true value most probably lies near the center of the scale display interval. This estimation equation should only be used when the calculated standard deviation is zero, or the $\mathrm{s}_{\mathrm{p}}$ is being estimated from display resolution, and the scale has passed the discrimination test.

\section{$s_{p}$ from measured reproducibility}

When desiring to ascertain the uncertainty of the scale during routine weighing operations, a check standard and control chart should be used to determine the long-term repeatability of the scale under varying operational conditions. This is called reproducibility, also evaluated as a standard deviation. Reproducibility is a measure of long-term repeatability and may be used in place of the short-term repeatability when calculating measurement uncertainty. The standard deviation of the control chart values will be used in the combined uncertainty as $s_{p}$. Multiple check standard loads may be required when the scale is used to measure loads that vary widely within the range of the scale. The check standard loads should be selected to represent the loads typically weighed on the scale. 


\section{Chapter 4: \\ Scale Calibrations Performed in an Uncontrolled Environment}

When using values from control charts to determine the $s_{p}$ value, attention must be given to the range of measurement results over which that value has been determined. When readings from a wide range of measurement results are included in the calculation of the $s_{p}$ value, an uncertainty calculated from that standard deviation is valid for the range over which the measurement results were obtained. However, the calculated uncertainty is sometimes greater than desired, or greater than is acceptable, and repair of the weighing device may not correct the problem. For those situations, it may be desirable to divide the data into measuring ranges and to calculate the standard deviation for the narrower measuring ranges. These standard deviations are applicable to the measuring range over which the data was obtained. The existence of multiple $s_{p}$ values requires the calculation of expanded uncertainty values for each affected measuring range.

\section{$s_{p}$ from manufacturer's specification}

The value for $\mathrm{s}_{\mathrm{p}}$ is best determined from repeated readings of a weight, whether shortterm or long-term. The manufacturer's specification sheet is not a recommended source for determining the uncertainty contribution due to repeatability. Manufacturers' specifications are established for a specific set of conditions that may not be representative of the actual environment in which the scale is tested and used. Manufacturers' specifications are an excellent tool when comparing the expected performance of one weighing device to another similar device, but they are established to indicate the expected performance of a family of weighing systems, not a specific weighing system. As the calibration uncertainty is being estimated for a specific weighing system, it is best to establish the calibration uncertainty contribution due to repeatability from measured data, not from an expected performance parameter. Manufacturers' specifications should not be used to estimate calibration uncertainty.

\section{Uncertainty due to display resolution $\left(u_{d r}\right)$}

When estimating the value of $s_{p}$ display resolution, an additional uncertainty component for indicator resolution must be included. This value $\left(\mathrm{u}_{\mathrm{dr}}\right)$ will also be equal to

$u_{d r}=\frac{1}{2} \frac{d}{\sqrt{3}}=0.29 d$ ( 0.29 times ' $\mathrm{d}$ '). This uncertainty component will not be included in the uncertainty calculations if repeated measurement results were used to determine a value for $\mathrm{s}_{\mathrm{p}}$. The effect of the display resolution uncertainty component will already have been part of the measured values and an additional uncertainty component is not required.

\section{Uncertainty of the standards $\left(u_{s}\right)$}

The uncertainty contribution of the standard masses used to perform the scale calibration may be estimated from one of two sources, the tolerance to which the masses have been tested, or the uncertainty associated with the calibration of the masses. Specific guidance follows.

\section{$u_{s}$ from standard weight tolerances}

When calibrating large capacity scales, the nominal values of the standard weights are typically used. In this situation, a portion of the tolerance to which the weights were tested is used as the standard uncertainty of the standards value, $\mathrm{u}_{\mathrm{s}}$, when calculating the calibration uncertainty. Only a portion of the tolerance is used as the tolerance is 


\section{Chapter 4: \\ Scale Calibrations Performed in an Uncontrolled Environment}

considered to follow a uniform probability distribution. The standard uncertainty of the standards is calculated as $u_{s}=\frac{\text { tolerance }}{\sqrt{3}}$ or (0.577 times the tolerance of the applied weights). When using multiple weights, the tolerance used in the $\mathrm{u}_{\mathrm{s}}$ calculation will be the sum of the tolerances for all of the weights used.

\section{$\mathbf{u}_{\mathrm{s}}$ from calibration uncertainties}

Standard mass uncertainties normally are reported as expanded uncertainties with reported coverage factor $(\mathrm{k})$. This expanded uncertainty must be divided by the stated coverage factor to obtain the standard uncertainty for the mass artifacts $\left(\mathrm{u}_{\mathrm{s}}\right)$.

\section{$u_{\mathrm{s}}$ with multiple standard weights}

When multiple weights are used, the most conservative value for the uncertainty of the mass calibrations is the linear sum of the uncertainties associated with each of the weights used simultaneously. For this situation $u_{s}=u_{s m 1}+u_{s m 2}+u_{s m 3}+\ldots . .+u_{s m i}$. While this method provides the most conservative estimate of standards uncertainty, it also typically provides the largest estimate for the standards uncertainty and may result in an uncertainty value that is greater than allowed by the customer's weighing process.

When a smaller uncertainty value is required and sufficient information about the weight calibrations is available, the root-sum-squared (RSS) value of the individual weight uncertainties may be used, but only if independence of the mass values is proven. Values are independent when no portion of the value of one weight affects the value of another. (If the same standard mass was used to calibrate each of the weights being used, the calibrations are not independent since the uncertainty and error of the standard's value contribute to the error and uncertainty for each of the weights. This is typically the case for weights on a large scale service truck as they are usually all calibrated at the same time.) Information concerning independence must be obtained from the calibrating organization. If the user is unsure of the independence of values, it should be assumed that the values are not independent. Thus, the sum of the individual uncertainties must be used. The RSS value of $u_{s}$ is to be used only if the actual measured values of recently calibrated mass artifacts were being used in the calibration of the scale. The equation for the RSS method is $u_{s}=\sqrt{u_{s m 1}^{2}+u_{s m 2}^{2}+u_{s m 3}^{2}+\ldots . .+u_{s m i}^{2}}$.

\section{Wind $\left(\mathbf{u}_{\mathbf{w}}\right)$}

The influence of the wind on large capacity scale systems is a very common contributor to uncertainty since most large capacity scales are installed in an outdoor environment. Depending on wind speed, direction, and the effect of nearby structures, it is possible to experience scale indication fluctuations many times the scale tolerance. In these situations, the service technician has to make a judgement call as to whether or not calibration is possible. This situation requires balancing the cost of re-scheduling the test against the ability to make a reasonable estimate of the true scale reading. It is recommended that the scale test be rescheduled for a time when the wind is less of an influence, thus minimizing the scale indicator fluctuations. 


\section{Chapter 4: \\ Scale Calibrations Performed in an Uncontrolled Environment}

\section{$u_{w}$ for scales with a recording system available}

If a technician decides to proceed with a scale calibration that is being affected by wind influences, an estimate of the additional uncertainty involved in the measurement must be included in the uncertainty calculations. Unless some means of recording a large number of scale indications over a period of time is available, the uncertainty due to wind influences is not a value that can be derived from statistical methods. When an indication recording system is available, an average and standard deviation of thirty or more readings should be calculated for each applied load value. The average of the measurement results will be reported as the scale indication and the standard deviation of the values will be included as part of the calibration uncertainty $\left(\mathrm{u}_{\mathrm{w}}\right)$.

\section{$u_{w}$ for scales without a recording system}

In situations where a recording device is not available, a scale technician will typically observe the weighing system indicator for a time and mentally calculate an average value based on his observations. The scale technician will report this estimated average as the scale indication for that applied load. The technician must also mentally note the maximum and minimum values observed. The reported scale indication will have an uncertainty equal to some portion of the observed fluctuations. As the difference between the estimated average and each observed scale indication is a fixed number of scale divisions, this uncertainty influence has a uniform probability distribution. The uncertainty will be estimated as $u_{w}=\frac{w}{\sqrt{3}}=0.577 w,(0.577$ times $w)$ where $w$ is the maximum difference between the reported scale indication and any observed scale indication.

\section{Vibration}

In the absence of wind effects that mask many uncertainty contributors, other influences, such as vibration, become more of a factor. Potential vibration sources include blasting, rock crushers, heavy equipment, railroad tracks, highways with heavy vehicular traffic, etc. An approach similar to that described for wind effects should be applied to suspected vibration effects and an uncertainty $\left(\mathrm{u}_{\mathrm{v}}\right)$ included in the calibration uncertainty calculations.

\section{Rain}

The effect of rain on a scale calibration is quite difficult to quantify, thus calibrations where rain is a factor are to be avoided. Each weight artifact used in a calibration will have its mass changed by an amount related to the quantity of water accumulated on its surface. In the calibration laboratory, large errors have been measured for mass artifacts that were covered with a layer of water. Additionally, the zero indication of the scale itself will vary as the quantity of water pooled on, or absorbed into, the scale deck varies during the test. This can also be a factor as a scale deck dries after the rain stops. Because this error is quite variable, depending on the amount of water accumulated, it is not possible to develop a correction that can be applied to a scale indication. For the same reason, developing an uncertainty factor for the effect of accumulated water is not possible. Calibration of scales where water accumulation is a factor is to be avoided. 


\section{Chapter 4: \\ Scale Calibrations Performed in an Uncontrolled Environment}

\section{Substitution loads}

Substitution loading involves applying a known load to a weighing system, removing that known load and then loading the weighing system with uncalibrated material to obtain a reading identical to that of the known load. The known load is then reapplied, along with the substitution load, effectively doubling the known load. According to current procedures, this process can be repeated two more times for a total of three substitutions, effectively multiplying the calibrated load by a factor of four. The substitution process results in an increased uncertainty as the substitution loads are being weighed by the system being calibrated. The uncertainty attributed to each substitution is equal to the repeatability factor $\left(\mathrm{s}_{\mathrm{p}}\right)$ calculated previously. Thus, the uncertainty contribution due to substitution tests $\left(\mathrm{u}_{\mathrm{sub}}\right)$ will be calculated as the number of substitutions times the calculated repeatability value. The result is included in the uncertainty as $\mathrm{u}_{\text {sub. }}$.

\section{Strain Load Tests}

Strain load testing involves loading the scale with an unknown load, setting the scale indication with the load as the reference, followed by applying additional known load to the scale deck. The additional uncertainty associated with a properly performed strain load test is negligible, because the possible measurement effects have been included as part of other uncertainty contributors. The error associated with an improperly performed strain load test is beyond the scope of this document.

Other measurement influences may contribute to the uncertainty of the calibration of a scale. The servicing technician must be knowledgeable of possible error contributors and must determine reasonable estimates of the uncertainty contribution of each by applying the guidance contained in this document.

\section{Calculation of the combined uncertainty}

The combined uncertainty, ' $u_{c}$ ', of the weighing system calibration will be calculated as the root-sum-squared of the influence factors.

$$
u_{c}=\sqrt{u_{s}^{2}+s_{p}^{2}+u_{w}^{2}+u_{s u b}^{2}+u_{d r}^{2}+u_{v}^{2}+u_{1}^{2}+u_{2}^{2}+u_{3}^{2}+\ldots+u_{i}^{2}}
$$

where $u_{i}$ are

any other uncertainty components that the scale technician wishes to include in the uncertainty calculations.

Remember:

- All of the uncertainty components must be in like terms of the mass units. Differing units, such as ${ }^{\circ} \mathrm{C}$ and $\mathrm{mg}$, cannot be combined. Convert the impact of the non-mass units to the appropriate mass units to calculate the uncertainty.

- All uncertainty components must be in terms of standard (one standard deviation) uncertainties.

\section{Calculating the expanded uncertainty}

The expanded uncertainty, ' $U$ ', is calculated by multiplying the value obtained for $\mathrm{u}_{\mathrm{c}}$ by the coverage factor, ' $\mathrm{k}$ ', for the confidence interval to be used. By convention, as defined in NIST Technical Note 1297, "Guidelines for Evaluating and Expressing the Uncertainty of NIST Measurement Results", a coverage factor of $\mathrm{k}=2$ is used for a confidence interval of 


\section{Chapter 4: \\ Scale Calibrations Performed in an Uncontrolled Environment}

approximately $95 \%$. The use of $\mathrm{k}$ values other than $\mathrm{k}=2$, requires an explanation of the reason for the deviation from convention.

\section{Evaluating the expanded uncertainty}

There are several things to consider when evaluating the uncertainty. First, does the final expanded uncertainty make sense? The expanded uncertainty must be at least ' $\mathrm{k}$ ' times greater than the largest uncertainty component included.

Second, does the calculated expanded uncertainty seem appropriate for the device tested? An uncertainty value seems unreasonable and should be investigated if the expanded uncertainty is calculated to be significantly less than one balance division. Likewise, if the calculated uncertainty is excessively large, that value should be investigated. Investigation should include verifying the use of proper evaluation techniques. Ensure that arithmetical errors were not the cause of the questionable uncertainty value.

Third, does the calculated uncertainty meet the requirements for weighing with that weighing device? Different quality systems have different requirements concerning the allowable measurement uncertainty; requirements may state that the uncertainty of a measuring device may not exceed $33 \%, 25 \%$, or even as little as $10 \%$, of the tolerance of the object being tested. Will the calculated uncertainty meet the requirements that are in place? If not, reexamine the entire calibration process for uncertainty contributors that can be reduced. Reduction may be accomplished by selection of more accurate standards, repair of the weighing device to obtain a smaller standard deviation, or perhaps making multiple measurements to determine the true repeatability of a device rather than using an estimated repeatability. Evaluate each uncertainty contributor, beginning with the most significant, to determine how it can legitimately be reduced until the required uncertainty level is obtained or until the decision is made that the weighing device cannot meet the quality requirements. Relocation or replacement of the scale may be required.

Remember, the reported calibration uncertainty is valid only for the environment in which it is determined. Temporarily improving the environment for the calibration, then returning it to the prior conditions for normal weighing operations invalidates the uncertainty statement. Engineering changes made to reduce calibration uncertainty must remain in place during normal weighing operations for the reduced uncertainty to remain valid.

\section{Reporting Uncertainty}

Reporting the expanded uncertainty value is no longer a matter of simply stating that a measurement result is ' $x \pm y$ ' where ' $x$ ' is the reported value and ' $y$ ' is the expanded uncertainty. The Guide to the Expression of Uncertainty in Measurement requires that you identify the various components of the uncertainty. You must also explain why that component was included and how it was evaluated. Specifically, the GUM provides a test of the stated uncertainty statement: "Has enough information been provided in a sufficiently clear manner that the result can be updated in the future if new information or data became available?" Another test is to ask: "Would another individual, not associated with the measurement process, be able to understand how the stated uncertainty was calculated and what was included; and then properly apply it to his/her own uncertainty calculation?" 


\section{Chapter 4:}

\section{Scale Calibrations Performed in an Uncontrolled Environment}

It must be understood that the measurement uncertainty must be calculated for each scale test load. The needs of the customer will determine whether a table format is used to report the uncertainty at each load, or the maximum uncertainty value of all test loads is reported as a single value covering the entire range of the weighing system. In either case, the uncertainty for each test load must be calculated and documented.

It is very important that uncertainty calculations be understandable so that the user can properly include the uncertainty components in their process uncertainty calculations. Some components of the uncertainty will need to be addressed differently from other components, and sufficient information must be available to make that possible. For example, when calculating the uncertainty of his production process, the customer would likely not wish to include reproducibility if the reproducibility value from a control chart of the measuring process was used to calculate the uncertainty of the scale calibration. To include the reproducibility value a second time would needlessly increase the expanded uncertainty of the production measurement process. Sufficient information must be provided to the user that it will be clear that the reproducibility should be included only once, in the original scale calibration uncertainty.

The importance of a clear, understandable and defensible uncertainty statement, based on a properly documented set of instructions, cannot be emphasized too strongly. The uncertainty statement is a critical portion of the calibration process. Write the uncertainty statement so that a future reader can make informed decisions concerning proper use of the uncertainty components provided.

The following tables provide a quick reference guide to the proper equation to use for calculating the calibration uncertainty in the most common situations. They also provide an example of a form that might be used to document the calibration uncertainty. 


\section{Chapter 4:}

Scale Calibrations Performed in an Uncontrolled Environment

\section{Quick Guide for Scale Calibration Uncertainties}

Reference information:

\begin{tabular}{|c|l|c|c|}
\hline \multicolumn{2}{|c|}{ Process ( $\left.\mathbf{S}_{\mathbf{p}}\right)$ Source (in order of desirability): } & $\begin{array}{c}\text { Distribution } \\
\text { Type }\end{array}$ & $\begin{array}{c}\text { Value to } \\
\text { use: }\end{array}$ \\
\hline 1 & $\begin{array}{l}\text { Calculated standard deviation at the test load from an up-to- } \\
\text { date control chart }\end{array}$ & Normal & As calculated \\
\hline 2 & $\begin{array}{l}\text { Calculated standard deviation from 10 or more readings of } \\
\text { same load over a short period of time }\end{array}$ & Normal & As calculated \\
\hline 3 & Estimated from scale division (discrimination test passed) & Uniform & $0.29 \mathrm{x}$ ' $\mathrm{d}$ ' \\
\hline 4 & $\begin{array}{l}\text { Estimated from scale division (discrimination test not } \\
\text { performed) }\end{array}$ & Uniform & $0.577 \mathrm{x}$ ' $\mathrm{d}$ ' \\
\hline
\end{tabular}

\begin{tabular}{|l|l|c|c|}
\hline $\begin{array}{l}\text { Standards (us) Sources } \\
\text { (in order of desirability): }\end{array}$ & $\begin{array}{c}\text { Distribution } \\
\text { Type }\end{array}$ & $\begin{array}{c}\text { Value to } \\
\text { use: }\end{array}$ \\
\hline 1 & Reported k=1 uncertainty from Report of Test & Normal & As calculated \\
\hline 2 & Tolerance of weights used & Uniform & $\begin{array}{c}0.577 \mathrm{x} \\
\text { tolerance }\end{array}$ \\
\hline Additional equations when using multiple standards & $u_{s}=\sqrt{u_{s m 1}^{2}+u_{s m 2}^{2}+u_{s m 3}^{2}+\ldots . .+u_{s m i}^{2}}$ \\
\hline a & Multiple standard masses (if independence is proven) & $u_{s}=u_{s m 1}+u_{s m 2}+u_{s m 3}+\ldots . .+u_{s m i}$. \\
\hline $\mathrm{b}$ & Multiple standard masses (if independence is unknown) & \\
\hline
\end{tabular}

\begin{tabular}{|ll|c|c|}
\hline Other uncertainty sources & $\begin{array}{c}\text { Distribution } \\
\text { Type }\end{array}$ & $\begin{array}{c}\text { Value to } \\
\text { use: }\end{array}$ \\
\hline Uncertainty due to wind effects $\left(\mathrm{u}_{\mathrm{w}}\right)$ & $(w=$ max deviation $)$ & Uniform & $0.577 w$ \\
\hline Uncertainty due to substitution loads $\left(\mathrm{u}_{\mathrm{sub}}\right)$ & & Uniform & $\mathrm{u}_{\mathrm{sub}}=\mathrm{s}_{\mathrm{p}}$ \\
\hline Uncertainty due to display resolution $\left(\mathrm{u}_{\mathrm{dr}}\right)$ & $($ see text $)$ & Uniform & 0 or $\mathrm{u}_{\mathrm{dr}}=\mathrm{s}_{\mathrm{p}}$ \\
\hline Uncertainty due to vibration effects $\left(\mathrm{u}_{\mathrm{v}}\right)$ & $(v=$ max deviation $)$ & Uniform & $0.577 v$ \\
\hline
\end{tabular}

Additionally, there may be other known measurement uncertainty contributors. Evaluate the calibration process carefully to ensure that all significant contributors are properly included in the uncertainty calculations. Consult the text of this Guide for additional guidance. 


\section{Chapter 4:}

Scale Calibrations Performed in an Uncontrolled Environment

Equipment Identification

\begin{tabular}{|l|c|c|c|c|}
\hline Manufacturer & Model & Serial & ECN & Other \\
\hline & & & & \\
\hline
\end{tabular}

\section{Uncertainty Worksheet}

at

Test Load

\begin{tabular}{|l|c|c|c|c|}
\hline Uncertainty Influence Description & Identifier & $\begin{array}{c}\text { Estimated } \\
\text { value }\end{array}$ & $\begin{array}{c}\text { Distribution } \\
\text { type } \\
\text { (Normal/Uniform) }\end{array}$ & $\begin{array}{c}\text { Estimated } \\
\text { Standard } \\
\text { Uncertainty }\end{array}$ \\
\hline Uncertainty of the standards used & $\mathrm{u}_{\mathrm{s}}$ & & & \\
\hline $\begin{array}{l}\text { Standard deviation of the process } \\
\text { (Determined at test load) }\end{array}$ & $\mathrm{s}_{\mathrm{p}}$ & & & \\
\hline Uncertainty due to & $\mathrm{u}_{1}$ & & & \\
\hline Uncertainty due to & $\mathrm{u}_{2}$ & & & \\
\hline Uncertainty due to & $\mathrm{u}_{3}$ & & & \\
\hline Uncertainty due to & $\mathrm{u}_{4}$ & & & \\
\hline Uncertainty due to & $\mathrm{u}_{5}$ & & & \\
\hline Uncertainty due to & $\mathrm{u}_{6}$ & & & \\
\hline Uncertainty due to & $\mathrm{u}_{6}$ & & & \\
\hline Uncertainty due to & $\mathrm{u}_{7}$ & & & \\
\hline
\end{tabular}

Combined standard uncertainty

$u_{c}=\sqrt{u_{s}^{2}+s_{p}^{2}+u_{w}^{2}+u_{s u b}^{2}+u_{d r}^{2}+u_{v}^{2}+u_{1}^{2}+u_{2}^{2}+u_{3}^{2}+\ldots .+u_{i}^{2}}$

\begin{tabular}{|l|l|l|}
\hline Expanded uncertainty & & \\
\hline $\mathrm{U}=\mathrm{k}\left(\mathrm{u}_{\mathrm{c}}\right), \mathrm{k}=$ & $\mathrm{U}=2$ is recommended & \\
\hline
\end{tabular}


Chapter 5:

Scale Calibrations Performed in a Semi-controlled Environment

\section{Chapter 5: Scale Calibrations in a Semi-Controlled Environment}




\section{Chapter 5: \\ Scale Calibrations Performed in a Semi-controlled Environment}

\section{Introduction}

Many general purpose scales are located in a semi controlled environment such as a grocery store or warehouse that minimizes many of the environmental influence factors that contribute to measurement uncertainty. Additionally, as most of these weighing devices have a relatively small capacity, it is possible to perform repeated measurements without severely affecting the time required to perform the calibration. The controlled environment and the ability to make repeated measurements simplify the process of calculating calibration uncertainty. Thus, service personnel are required to make fewer subjective decisions.

The following outlines the process that scale service personnel should use to calculate the uncertainty associated with the scale testing process.

\section{Specify the Process and Equation}

Write down a clear concise statement of what is being measured and the relationship between it and the parameters on which it depends. Remember, the scale indication is being tested, not the mass of the standard mass artifacts.

Example: $y=(m x+b) \pm U$ where;

$\mathrm{y}$ is the scale indication, $\mathrm{m}$ is the sensitivity of the weighing device, $\mathrm{x}$ is the applied load, $\mathrm{b}$ is the zero offset, and $\mathrm{U}$ is the assigned measurement uncertainty.

Ideally, $\mathrm{b}=0$ if the scale indication was properly zeroed, and $\mathrm{m}=1$ because the scale indicates one mass unit for each mass unit applied.

\section{2, 3 \& 4. Uncertainty Identification, Characterization and Quantification}

The uncertainty associated with the calibration of a general purpose scale is comprised of many influence factors. A cause and effect diagram is used here to identify the factors and to show their relationship to other factors. 


\section{Chapter 5:}

\section{Scale Calibrations Performed in a Semi-controlled Environment}

\section{Sample Cause and Effect Diagram}

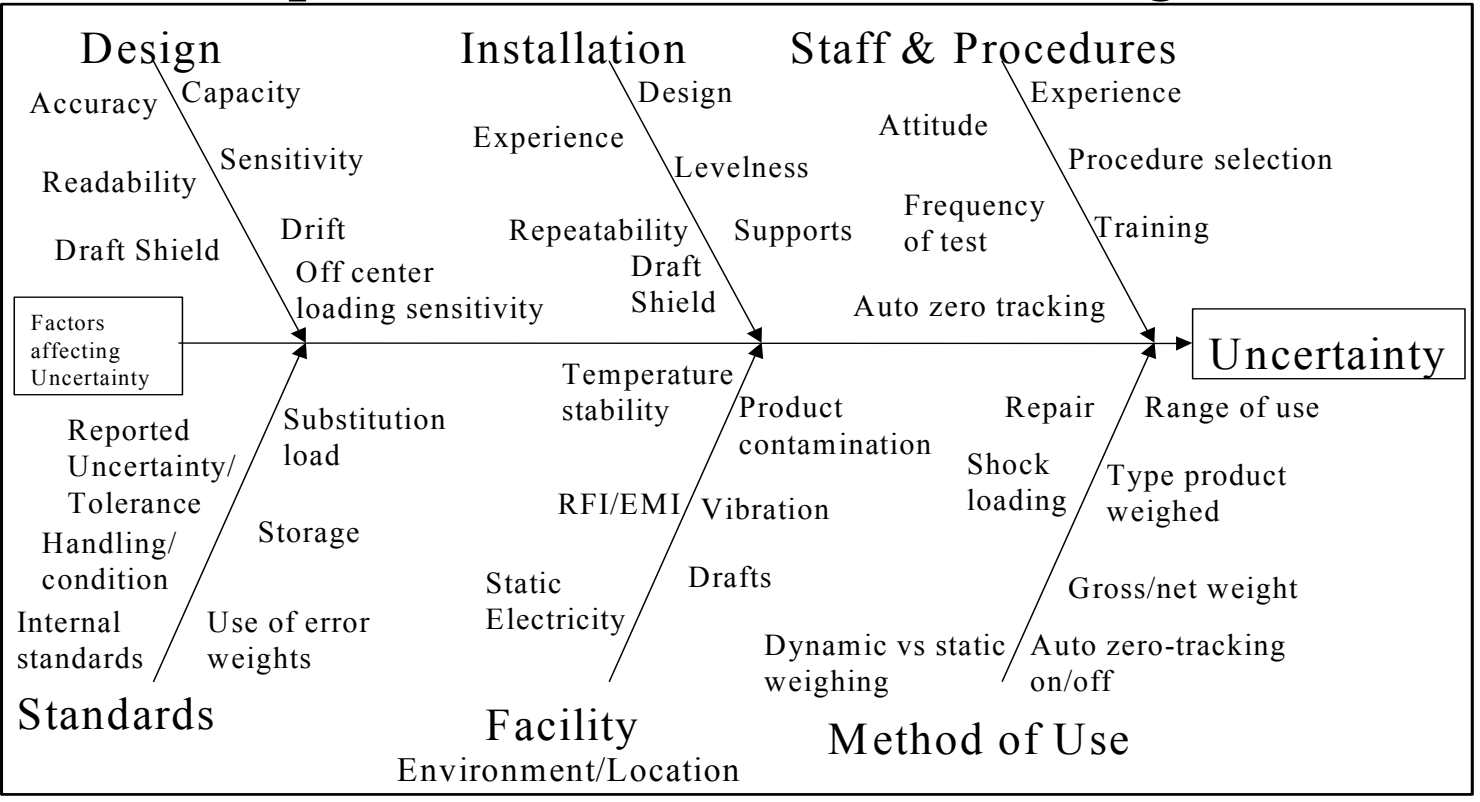

* not all inclusive

In addition to the influences shown on the diagram, other possible causes of uncertainty are standard mass errors, thermal equilibration of standards, scale warm-up, power-line noise, etc.

Evaluate each uncertainty influence for its significance. Consider an uncertainty component significant if it can cause a change in the value of the second most significant digit, leading zeros excluded, when included in the uncertainty calculations. For example, if the expanded uncertainty value is currently $0.052 \mathrm{~kg}$ and including the value of an uncertainty contributor causes the new value to be $0.053 \mathrm{~kg}$, that contributor is considered significant. If no change results in the second significant digit, the ' 2 ', the contributor is not considered significant for that particular calibration. When an uncertainty contributor is considered significant, a value for that uncertainty component must be included in the uncertainty calculations for that calibration process. Whether included in the uncertainty calculations or not, the GUM requires that the process of performing the evaluation, and the results of the evaluation, be documented for each known uncertainty contributor.

Many of the influence factors contained in the Sample Cause and Effect Diagram are addressed in the following paragraphs. The individual(s) performing the test must decide how to deal with each influence, whether by avoidance, correction or inclusion as part of the uncertainty.

The service staff must evaluate the situation surrounding the scale and must eliminate or minimize as many of the measurement influence factors as possible. Engineering changes put in place to minimize a measurement influence must remain in place at all times for the calibration uncertainty to remain valid. 


\section{Chapter 5:}

\section{Scale Calibrations Performed in a Semi-controlled Environment}

Levelness of the scale should be checked and corrected if necessary.

Drafts should be eliminated by the installation of draft shields, air diffusers or by redirecting air vents, or closing doors. These draft elimination measures must be in place at all times (including during use) for the calibration uncertainty statement to remain valid during daily use.

Off-center loading errors should be evaluated and corrected before recording final calibration data.

Thermal equilibrium of the scale should be ensured by keeping the scale in an energized state (i.e., turned on) for sufficient time to ensure that all circuitry and hardware has reached a stable temperature.

Vibration sources must be identified and eliminated or minimized to limit the vibration levels to which the weighing device is exposed during daily use, as well as during calibration.

Zero-tracking features should be disabled to avoid undetectable zero indication errors. Zero-tracking is designed to eliminate minor changes in scale indication due to drift of the weighing system and may be turned 'on' to maintain the 'zero' indication of the weighing device. Due to the correction limits included in the system programming regarding quantity and motion detection, detrimental effects on measurement results are typically not evident. However, service personnel may, while attempting to load the pan in a slow, gentle manner encounter times that the zero tracking circuitry will cause an offset in the indication. While this would be an unusual occurrence, service personnel must be aware of the possibility of such errors and take steps to prevent them from occurring.

Mass Standards must be brought into close proximity to the scale to ensure thermal equilibrium with the scale and surrounding environment. Thermal stabilization times for weights typically used for a scale in this environment are not specified, but sufficient time must be allowed to ensure that condensation is not present on the weights.

Standard mass error effects can be minimized by using the mass values determined during calibration of the mass artifacts. For most scales used in a semi-controlled environment this will not be necessary as the tolerances of the scales and standard masses have been set to minimize the effects of the standard mass errors. The concept is presented here as an option should correction be desirable. The standard mass uncertainty for general purpose scales is normally based on the tolerance of the mass standards.

However, if the mass corrections of the standard masses are used, the reported calibration uncertainty of the mass calibration must be used as $u_{s}$. The complete calculation of $u_{s}$ is covered in a later section of this chapter. 


\section{Chapter 5: \\ Scale Calibrations Performed in a Semi-controlled Environment}

Scale indication drift errors should be corrected to the maximum extent possible. Though slight drift in the indicated value is somewhat normal, significant indication drift may indicate thermal instability of the weighing system. Allowing a longer temperature stabilization period for the weighing device and standard mass artifacts can minimize drift due to thermal instability. Exercising the weighing system may also minimize drift. Repeatedly applying and removing loads within the range of the device causes the electronic and mechanical components of the system to acquire a thermal equilibrium of use. If indication drift is excessive and cannot be eliminated by the means described, other corrective action must be taken.

RFI/EMI susceptibility tests should be performed. Changes in indication due to random RFI/EMI influences can be difficult to detect during normal use and may be interpreted as repeatability errors or drift. Corrective action should be taken if RFI/EMI susceptibility is detected.

Note: RFI/EMI sources include two-way radios, cell phones and other electronic devices. Laboratories are available specializing in detecting and measuring RFI/EMI.

Power-line noise or variations can cause random display indications to occur. The specific cause of these random indications may be difficult to determine, but will affect the repeatability of the weighing system. Where possible, it is best that scales be powered by a dedicated power circuit or be powered by a AC line conditioner to prevent these measurement influences.

Operator errors result when operators are inadequately trained. All operators of weighing devices should have proper training and be knowledgeable about the weighing instrument and the process in which it is used. Inadequately trained personnel may record data with significant errors, improperly influencing critical process decisions. Weighing system operators must be equipped with correct and complete work instructions to minimize the likelihood of operator error.

Careful planning or suitable corrective action will minimize or eliminate many scale measurement uncertainty sources. However, there are several uncertainty influences that cannot be eliminated. The results of these influences must be included in the calibration uncertainty calculations. Each are discussed in the following paragraphs.

\section{Process standard deviation $\left(s_{p}\right)$}

The source of a value for $\mathrm{s}_{\mathrm{p}}$ can be based on scale repeatability, scale reproducibility or the size of a scale division. Each are discussed below.

\section{$s_{p}$ from measured repeatability}

Repeatability is a measure of a scale's ability to produce the same indication every time the same weight, under identical conditions, is placed on the sensing device.

Repeatability is normally presented as a standard deviation and is normally determined by repeated measurements of a specific weight. At least seven measurement results of a weight are required to calculate the repeatability or standard deviation of the scale.

Increasing the number of measurement results provides greater confidence in the value. 


\section{Chapter 5:}

\section{Scale Calibrations Performed in a Semi-controlled Environment}

A minimum of thirty measurement results is preferred when calculating a standard deviation. The calculated standard deviation obtained in this manner is a measure of the weighing system's ability to repeat measurement results over a short time interval and does not represent the long-term reproducibility.

Due to scale resolution, it is possible to make seven or more measurements with every measurement resulting in the same value. A true scale standard deviation of zero is not statistically possible, though the standard deviation may be less than one display increment (d). In this situation, assuming that a control chart of a check standard is not available, the standard deviation of the scale can be estimated as $s_{p}=\frac{d}{\sqrt{3}}=0.577 d$ ( 0.577 times the value of ' $\mathrm{d}$ ') as described in the GUM.

If it is possible to perform a discrimination test as described in NIST Handbook 44, N.1.5 and T.N.7.1 or OIML R 76-1, A.4.8, another equation may be used. That equation is: $s_{p}=\frac{1}{2} \frac{d}{\sqrt{3}}=0.29 d(0.29$ times the value of ' $\mathrm{d}$ ') since passing the discrimination test proves that the true value most probably lies near the center of the scale display interval. This estimation equation should only be used when the calculated standard deviation is zero and the scale has passed a discrimination test as described in NIST Handbook 44, N.1.5 and T.N.7.1 or OIML E 76-1, A.4.8.

\section{$s_{p}$ from measured reproducibility}

When desiring to ascertain the uncertainty of the scale during everyday weighing operations, a check standard and control chart should be used to determine the long-term repeatability of the scale, under varying operational conditions. This is called reproducibility, also evaluated as a standard deviation. Reproducibility is a measure of long-term repeatability and is used in place of the short-term repeatability when calculating measurement uncertainty. The value will be included in the combined uncertainty as $\mathrm{s}_{\mathrm{p}}$.

When using values from control charts to determine the $s_{p}$ value, attention must be given to the range of measurement results over which that value has been determined. When readings from a wide range of measurement results are included in the calculation of the $\mathrm{s}_{\mathrm{p}}$ value and the resulting standard deviation is acceptable, an uncertainty calculated from that standard deviation is valid for the range over which the measurement results were obtained. However, sometimes the calculated uncertainty is greater than desired or greater than is acceptable. Repair of the weighing device may not suitably correct the problem. For those situations, it might be desirable to divide the data into measuring ranges and to calculate the standard deviation for the narrower measuring ranges. These standard deviations would be applicable to the measuring range over which the data was obtained. Especially in a calibration facility, a scale may have multiple $s_{p}$ values, each covering a different portion of the scale measuring range. The existence of multiple $s_{p}$ values requires the calculation of expanded uncertainty values for each affected measuring range. 


\section{Chapter 5: \\ Scale Calibrations Performed in a Semi-controlled Environment}

\section{$s_{p}$ from manufacturer's specifications}

The value for $s_{p}$ is best determined from repeated readings of a weight, whether shortterm or long-term. The manufacturer's specification sheet is not a recommended source for determining the uncertainty contribution due to repeatability. Manufacturers' specifications are established for a specific set of conditions that may not be representative of the actual environment in which the scale is tested and used. Manufacturers' specifications are an excellent tool when comparing the expected performance of one weighing device to another similar device, but they are established to indicate the expected performance of a family of weighing systems, not a specific weighing system. As the calibration uncertainty is being estimated for a specific weighing system, it is best to establish the calibration uncertainty contribution due to repeatability from measured data, not from an expected performance parameter. Manufacturers' specifications should not be used to estimate calibration uncertainty.

\section{Uncertainty due to display resolution $\left(u_{d r}\right)$}

When the repeatability $\left(s_{p}\right)$ is estimated from display resolution, an additional uncertainty component for indicator resolution must be included. This value $\left(\mathrm{u}_{\mathrm{dr}}\right)$ will be equal to $u_{d r}=\frac{1}{2} \frac{d}{\sqrt{3}}=0.29 d$ (0.29 times the value of ' $\mathrm{d}$ '). This uncertainty component should not be included in the uncertainty calculations if repeatability is measured by making repeated measurements. The effect of the display resolution uncertainty component will have been part of the measured values and an additional uncertainty component is not required.

\section{Uncertainty of the standards $\left(u_{s}\right)$}

The uncertainty contribution of the standard masses used to perform the scale calibration may be estimated from one of two sources, the tolerance to which the masses have been tested, or the uncertainty associated with the calibration of the masses. Specific guidance follows.

\section{$u_{s}$ from standard weight tolerances}

When calibrating large capacity scales, the nominal values of the standard weights are typically used. In this situation, a portion of the tolerance to which the weights were tested is used as the standard uncertainty of the standards value, $\mathrm{u}_{\mathrm{s}}$, when calculating the calibration uncertainty. Only a portion of the tolerance is used as the tolerance is considered to follow a uniform probability distribution. The standard uncertainty of the standards is calculated as $u_{s}=\frac{\text { tolerance }}{\sqrt{3}}$ or $(0.577$ times the tolerance of the applied weights). When using multiple weights, the tolerance used in the $u_{\mathrm{s}}$ calculation will be the sum of the tolerances for all of the weights used.

\section{$\mathbf{u}_{\mathrm{s}}$ from calibration uncertainties}

Standard mass uncertainties normally are reported as expanded uncertainties, having been calculated by combining the various standard uncertainties that influenced the mass calibration process. The combined standard uncertainty has then been multiplied by a stated coverage factor $(\mathrm{k})$ to obtain the expanded uncertainty. This expanded uncertainty 


\section{Chapter 5:}

\section{Scale Calibrations Performed in a Semi-controlled Environment}

must be divided by the coverage factor to obtain a standard uncertainty for the mass artifacts, $\mathrm{u}_{\mathrm{s}}$.

\section{$u_{s}$ with multiple standard weights}

When multiple weights are used, the most conservative value for the uncertainty of the mass calibrations is the sum of the uncertainties associated with each of the weights used simultaneously. For this situation $u_{s}=u_{s m 1}+u_{s m 2}+u_{s m 3}+\ldots . .+u_{s m i}$. While this method provides the most conservative estimate of standards uncertainty, it also typically provides the largest estimate for the standards uncertainty and may result in an uncertainty value greater than is allowed by the customer's weighing process.

When a smaller uncertainty value is required and sufficient information about the weight calibrations is available, the root-sum-squared (RSS) value of the individual weight uncertainties may be used, but only if true independence of the mass values is proven. Values are independent when no portion of the value of one weight affects the value of another. (If the same standard mass was used to calibrate each of the weights being used, the calibrations are not independent since the uncertainty and error of the standard's value contribute to the error and uncertainty for each of the weights. Weights of the same nominal mass, in a kit, are normally calibrated using the same standard and the values are not independent.) Information concerning independence must be obtained from the calibrating organization. If the user is unsure of the independence of values, it should be assumed that the values are not independent, and the sum of the individual uncertainties must be used. The RSS value of $\mathrm{u}_{\mathrm{s}}$ will be used only if the actual measured values of the mass artifacts were being used in the calibration of the scale.

The equation for the root-sum-squared method is $u_{s}=\sqrt{u_{s m 1}^{2}+u_{s m 2}^{2}+u_{s m 3}^{2}+\ldots . .+u_{s m i}^{2}}$.

\section{Calculation of the combined uncertainty}

The combined uncertainty, ' $u_{\mathrm{c}}$ ', of the weighing system calibration will be calculated as the root-sum-squared of the influence factors.

$u_{c}=\sqrt{u_{s}^{2}+s_{p}^{2}+u_{d r}^{2}+u_{1}^{2}+u_{2}^{2}+u_{3}^{2}+\ldots .+u_{i}^{2}}$ where $u_{\mathrm{i}}$ are any other uncertainty components that the scale technician wishes to include in the uncertainty calculations.

Remember:

- All of the uncertainty components must be in terms of the mass units of the scale. Differing units, such as ${ }^{\circ} \mathrm{C}$ and $\mathrm{mg}$, cannot be combined. Convert the impact of the nonmass units to the appropriate mass units to calculate the uncertainty.

- All uncertainty components must be in terms of standard (one standard deviation) uncertainties.

\section{Calculating the expanded uncertainty}

The expanded uncertainty, ' $U$ ', is calculated by multiplying the value obtained for $\mathrm{u}_{\mathrm{c}}$ by the coverage factor, ' $\mathrm{k}$ ', for the confidence interval to be used. By convention, as defined in NIST Technical Note 1297, "Guidelines for Evaluating and Expressing the Uncertainty of NIST Measurement Results", a coverage factor of $\mathrm{k}=2$ is used for a confidence interval of 


\section{Chapter 5: \\ Scale Calibrations Performed in a Semi-controlled Environment}

approximately $95 \%$. The use of $\mathrm{k}$ values other than $\mathrm{k}=2$ requires an explanation of the reason for the deviation from convention.

\section{Evaluating the expanded uncertainty}

There are several things to consider when evaluating the uncertainty.

First, does the final expanded uncertainty make sense? The expanded uncertainty must be at least ' $\mathrm{k}$ ' times greater than the largest uncertainty component included.

Second, does the calculated expanded uncertainty seem appropriate for the tested device? An uncertainty value seems unreasonable and should be investigated if the expanded uncertainty is calculated to be significantly less than one balance division. Likewise, if the calculated uncertainty is excessively large, that value should be investigated. Investigation should include verifying the use of proper evaluation techniques. Ensure that arithmetical errors were not the cause of the questionable uncertainty value.

Third, does the calculated uncertainty meet the requirements of the tests that will be performed using the weighing device? Different quality systems have different requirements concerning the allowable measurement uncertainty; requirements such that the uncertainty of a measuring device may not exceed $33 \%, 25 \%$, or even as little as $10 \%$, of the tolerance of the object being tested. Will the calculated uncertainty meet any such requirements that may be in place? If not, examine the entire calibration process for uncertainty contributors that can be reduced. Reduction may be accomplished by selection of more accurate standards, repair of the weighing device to obtain a smaller standard deviation, or perhaps making multiple measurements to determine the true repeatability of a device rather than using an estimated repeatability. Evaluate each uncertainty contributor, beginning with the most significant, to determine how it can legitimately be reduced until the required uncertainty level is obtained or until the decision is made that the weighing device cannot meet the quality requirements and must be replaced or that the weighing system must be moved to a more hospitable environment.

Remember, the reported calibration uncertainty is valid only for the environment in which it is determined. Temporarily improving the environment for the calibration, then returning it to the prior conditions for normal weighing operations invalidates the uncertainty statement. Engineering changes made to reduce calibration uncertainty must remain in place during normal weighing operations.

\section{Reporting Uncertainty}

Reporting the expanded uncertainty value is no longer a matter of simply stating that a measurement result is ' $x \pm y$ ' where ' $x$ ' is the reported value and ' $y$ ' is the expanded uncertainty. The Guide to the Expression of Uncertainty in Measurement requires that you identify the various components of the uncertainty. You must also explain why that component was included and how it was evaluated. Specifically, the GUM provides a test of the stated uncertainty statement: "Has enough information been provided in a sufficiently clear manner that the result can be updated in the future if new information or data became available?" Another test is to ask: "Would another individual, unassociated with the 


\section{Chapter 5: \\ Scale Calibrations Performed in a Semi-controlled Environment}

measurement process, be able to understand how the stated uncertainty was calculated and what was included, and then properly apply it to his/her own uncertainty calculation?"

It must be understood that the measurement uncertainty must be calculated for each scale test load. The needs of the customer will determine whether a table format is used to report the uncertainty at each load, or the maximum uncertainty value of all test loads is reported as a single value covering the entire range of the weighing system. In either case, the uncertainty for each test load must be calculated and documented.

It is very important that uncertainty calculations be understandable so that the user can properly include the uncertainty components in their process uncertainty calculations. Some components of the uncertainty will need to be addressed differently from other components, and sufficient information must be available to make that possible. For example, when calculating the uncertainty of his production process, the customer would likely not wish to include reproducibility if the reproducibility value from a control chart of the measuring process was used to calculate the uncertainty of the balance calibration. To include the reproducibility value a second time would needlessly increase the expanded uncertainty of the production measurement process. Sufficient information must be provided to the user so that it will be clear that the reproducibility should be included only once, in the originally reported scale calibration uncertainty.

The importance of a clear, understandable and defensible uncertainty statement, based on a properly documented set of instructions, cannot be emphasized too strongly. The uncertainty statement is a critical portion of the calibration process. Write the uncertainty statement so that a future reader can make informed decisions concerning proper use of the uncertainty components provided.

The following tables provide a quick reference guide to the proper equation to use for calculating the calibration uncertainty in the most common situations. They also provide an example of a form that might be used to document the calibration uncertainty. 


\section{Chapter 5:}

Scale Calibrations Performed in a Semi-controlled Environment

\section{Quick Guide for Scale Calibration Uncertainties}

\section{Reference information:}

\begin{tabular}{|c|l|c|c|}
\hline \multicolumn{2}{|c|}{ Process $\left(\mathbf{S}_{\mathbf{p}}\right)$ Source (in order of desirability): } & $\begin{array}{c}\text { Distribution } \\
\text { Type }\end{array}$ & $\begin{array}{c}\text { Value to } \\
\text { use: }\end{array}$ \\
\hline 1 & $\begin{array}{l}\text { Calculated standard deviation at the test load from an up-to- } \\
\text { date control chart }\end{array}$ & Normal & As calculated \\
\hline 2 & $\begin{array}{l}\text { Calculated standard deviation from 10 or more readings of } \\
\text { same weight over a short period of time }\end{array}$ & Normal & As calculated \\
\hline 3 & Estimated from scale division (discrimination test passed) & Uniform & $0.29 \mathrm{x}$ ' $\mathrm{d}$ ' \\
\hline 4 & $\begin{array}{l}\text { Estimated from scale division (discrimination test not } \\
\text { performed) }\end{array}$ & Uniform & $0.577 \mathrm{x}$ ' $\mathrm{d}$ ' \\
\hline
\end{tabular}

\begin{tabular}{|l|l|c|c|}
\hline \multicolumn{2}{|l|}{$\begin{array}{l}\text { Standards ( } \\
\text { (in order of desirability): }\end{array}$} & $\begin{array}{c}\text { Distribution } \\
\text { Type }\end{array}$ & $\begin{array}{c}\text { Value to } \\
\text { use: }\end{array}$ \\
\hline 1 & Reported k=1 uncertainty from Report of Test & Normal & As calculated \\
\hline 2 & Tolerance of weight used & Uniform & $\begin{array}{c}0.577 \mathrm{x} \\
\text { tolerance }\end{array}$ \\
\hline Additional equations when using multiple standards & $u_{s}=\sqrt{u_{s m 1}^{2}+u_{s m 2}^{2}+u_{s m 3}^{2}+\ldots . .+u_{s m i}^{2}}$ \\
\hline a & Multiple standard masses (if independence is proven) & $u_{s}=u_{s m 1}+u_{s m 2}+u_{s m 3}+\ldots . .+u_{s m i}$. \\
\hline $\mathrm{b}$ & Multiple standard masses (if independence is unknown) &
\end{tabular}

\begin{tabular}{|l|l|c|}
\hline Other uncertainty sources & $\begin{array}{c}\text { Distribution } \\
\text { Type }\end{array}$ & $\begin{array}{c}\text { Value to } \\
\text { use: }\end{array}$ \\
\hline Uncertainty due to display resolution $\left(\mathrm{u}_{\mathrm{dr}}\right) \quad$ (see text) & Uniform & 0 or $\mathrm{u}_{\mathrm{dr}}=\mathrm{s}_{\mathrm{p}}$ \\
\hline
\end{tabular}

Additionally, there may be other known measurement uncertainty contributors. Evaluate the calibration process carefully to ensure that all significant contributors are properly included in the uncertainty calculations. Consult the text of this Guide for additional guidance. 


\section{Chapter 6:}

Sample Calculations and Recommendations for Reducing Uncertainty

\section{Equipment Identification}

\begin{tabular}{|l|l|l|l|l|}
\hline Manufacturer & Model & Serial & ECN & Other \\
\hline & & & & \\
& & & & \\
\hline
\end{tabular}

\section{Uncertainty Worksheet}

at Test Load

\begin{tabular}{|l|c|c|c|c|}
\hline Uncertainty Influence Description & Identifier & $\begin{array}{c}\text { Estimated } \\
\text { value }\end{array}$ & $\begin{array}{c}\text { Distribution } \\
\text { type } \\
\text { (Normal/Uniform) }\end{array}$ & $\begin{array}{c}\text { Estimated } \\
\text { Standard } \\
\text { Uncertainty }\end{array}$ \\
\hline Uncertainty of the standards used & $\mathrm{u}_{\mathrm{s}}$ & & & \\
\hline $\begin{array}{l}\text { Standard deviation of the process } \\
\text { (Determined at coad) }\end{array}$ & $\mathrm{s}_{\mathrm{p}}$ & & & \\
\hline Uncertainty due to & $\mathrm{u}_{1}$ & & & \\
\hline Uncertainty due to & $\mathrm{u}_{2}$ & & & \\
\hline Uncertainty due to & $\mathrm{u}_{3}$ & & & \\
\hline Uncertainty due to & $\mathrm{u}_{4}$ & & & \\
\hline Uncertainty due to & $\mathrm{u}_{5}$ & & & \\
\hline Uncertainty due to & $\mathrm{u}_{6}$ & & & \\
\hline Uncertainty due to & $\mathrm{u}_{6}$ & & & \\
\hline Uncertainty due to & & & \\
\hline
\end{tabular}

\begin{tabular}{|l|l|}
\hline Combined standard uncertainty \\
\hline$u_{c}=\sqrt{u_{s}^{2}+s_{p}^{2}+u_{d r}^{2}+u_{1}^{2}+u_{2}^{2}+u_{3}^{2}+u_{4}^{2}+u_{5}^{2}+\ldots .+u_{i}^{2}} \quad \mathrm{u}_{\mathrm{c}}=$ & \\
\hline
\end{tabular}

\begin{tabular}{|lll|l|}
\hline Expanded uncertainty & \\
\hline $\mathrm{U}=\mathrm{k}\left(\mathrm{u}_{\mathrm{c}}\right), \mathrm{k}=\ldots \mathrm{k}=2$ is recommended & $\mathrm{U}=$ & \\
\hline
\end{tabular}


Chapter 6:

Sample Calculations and Recommendations for Reducing Uncertainty

\section{Chapter 6: \\ Sample Calculations and Recommendations for Reducing \\ Uncertainty}




\section{Chapter 6:}

\section{Sample Calculations and Recommendations for Reducing Uncertainty}

\section{Introduction}

Evaluating the uncertainty of a scale and balance calibration process can be extremely complex depending on the location, capacity, design, readability, amount of calibrated load available, air currents and a host of other factors. It is not possible to provide an example that will address all situations, but the examples given, and the accompanying discussion, provide some insight into the process to be completed for every scale or balance calibration

\section{Sample Uncertainty Calculation \#1 (Relates to Chapter 3)}

The following example of an uncertainty calculation for a $200 \mathrm{~g}$ laboratory balance calibration will provide insight into the process that must be used to analyze a balance calibration and evaluate the associated uncertainty. (The two test loads, $50 \mathrm{~g}$ and $200 \mathrm{~g}$, are used for demonstration purposes only. Consult the appropriate procedural documents for full test requirements.)

This balance is a Class I balance with a maximum load of 205 grams and a readability of $1 \mathrm{mg}$. It is located in a facility that deals with materials that are not hazardous, but are unpleasant to work with due to an offensive odor. Due to the unpleasant odor, the balance is located inside a fume hood.

A $100 \mathrm{~g}$ to $1 \mathrm{mg}$ set of Class $\mathrm{E}_{1}$ weights is used to perform the calibration and the nominal values of the weights will be used. When preparing for the calibration, the balance user switched the fume hood off so that the service personnel did not have to listen to the drone of the fan. In addition, other equipment was removed from the fume hood. Typically, a small drying oven, and a small sample shaker are also located inside the fume hood near the balance. All are connected to a common power source. The environmental conditions are stable throughout the calibration process.

NIST Handbook 44 tolerances will be used even though this balance is not used for commercial sale of goods and is not technically within the regulatory jurisdiction of any Weights and Measures program. No other tolerance guidance is available.

The Class I balance has a tolerance of

\section{Class I Maintenance Tolerances}

\begin{tabular}{|l|l|}
\hline Range tested $(d)$ & Tolerance $($ d) HB 44, Table 6 \\
\hline 0 to 50000 & \pm 1 \\
\hline 50001 to 200000 & \pm 2 \\
\hline $200001+$ & \pm 3 \\
\hline
\end{tabular}

For the sample calculation, the tolerance at the applied load will be

\begin{tabular}{|l|l|}
\hline Test Load Applied & Tolerance \\
\hline $50000 \mathrm{~d}(50 \mathrm{~g})$ & $\pm 1 \mathrm{~d}(1 \mathrm{mg})$ \\
\hline $200000 \mathrm{~d}(200 \mathrm{~g})$ & $\pm 2 \mathrm{~d}(2 \mathrm{mg})$ \\
\hline
\end{tabular}

These test points were selected since they cause indications at the upper extreme of the individual tolerance ranges. Consult the appropriate procedural document for full test requirements. 


\section{Chapter 6:}

\section{Sample Calculations and Recommendations for Reducing Uncertainty}

Due to the small weights employed in this calibration, multiple measurements are performed to measure the repeatability of the balance at a $100 \mathrm{~g}$ load. Ten readings were recorded: the ten values are identical, therefore the calculated $\mathrm{s}_{\mathrm{p}}=$ zero $(0)$.

How will the uncertainty of the calibration be determined?

\section{Specify the process and equation}

The indicated values of the balance loads are a function of the applied load and the associated uncertainty. A very basic statement of the measurement equation would be:

Indication $=$ applied load \pm Uncertainty or $\mathrm{y}=\mathrm{mx}+\mathrm{b} \pm \mathrm{U}$. Uncertainty equals

$$
U=2 * \sqrt{u_{s}^{2}+s_{p}^{2}+u_{1}^{2}+u_{2}^{2}+u_{3}^{2}+\ldots .+u_{i}^{2}}
$$

\section{Identify and characterize the uncertainty sources}

The uncertainty sources that are significant for this calibration are:

the uncertainty of the standard weights,

the standard deviation of the balance

\section{Significant and uncorrectable factors}

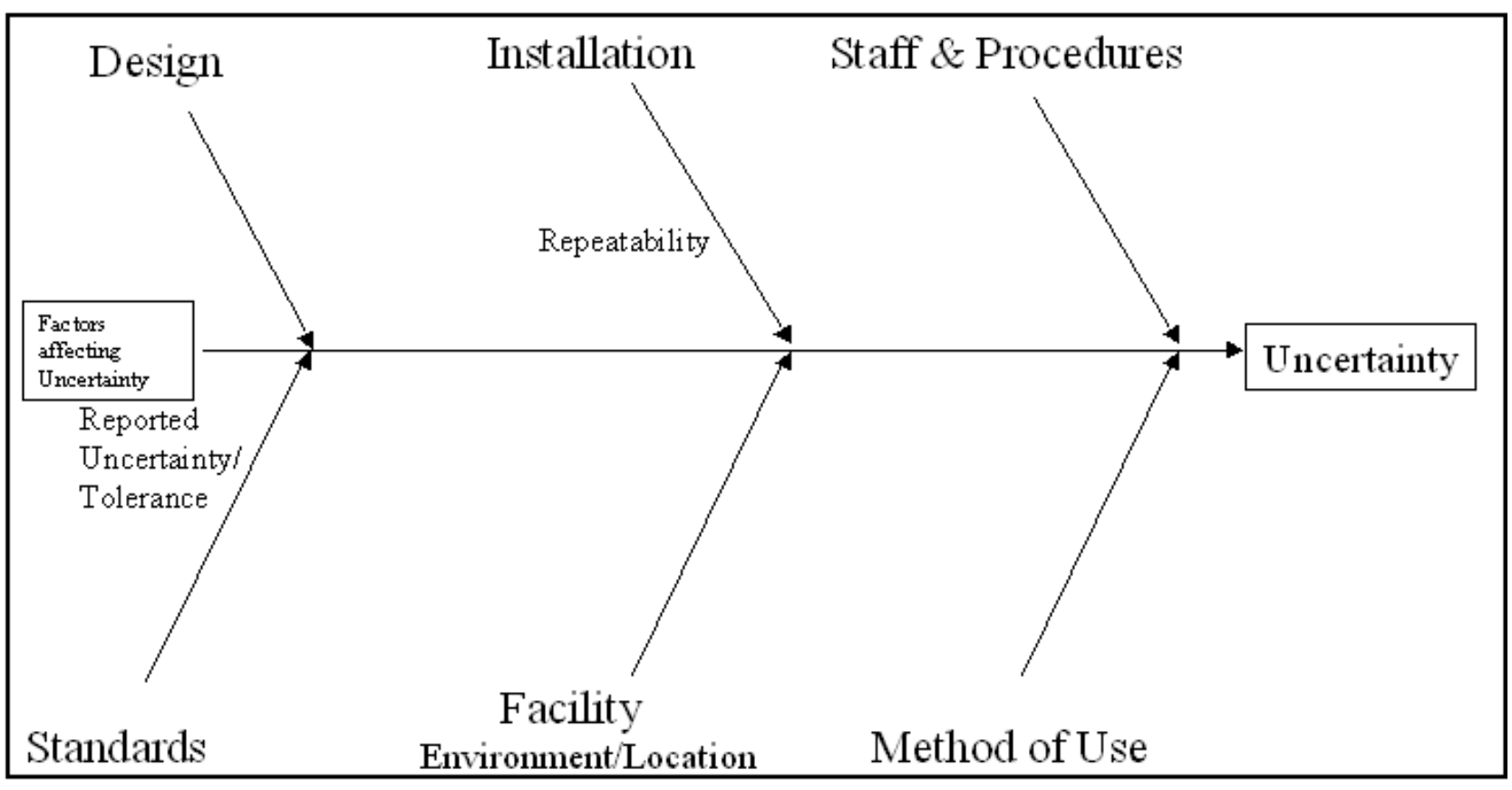

\section{Quantify the identified uncertainty components}

The uncertainty of the standard weights is taken to be equal to the sum of the tolerances of the OIML Class $\mathrm{E}_{1}$ weights used at each applied load. This calculates to be: $\pm 0.15 \mathrm{mg}$ at $200 \mathrm{~g}$, and \pm $0.030 \mathrm{mg}$ at 50 grams.

The standard deviation of the 10 measurement results obtained at $100 \mathrm{~g}$ calculates to a standard deviation of zero, since all of the indications were identical. A standard deviation of zero is not statistically possible, but is a result of having recorded only 10 indicated readings. If all possible 


\section{Chapter 6:}

\section{Sample Calculations and Recommendations for Reducing Uncertainty}

measurement results were obtained at $100 \mathrm{~g}$, there would be an infinite number of readings. Statistics shows that the standard deviation, $\mathrm{s}_{\mathrm{p}}$, would be approximately equal to some portion of one scale division, or $1 \mathrm{mg}$.

\section{Convert the measurement influences to standard deviation equivalents}

Using the text and the Quick Guide table from Chapter 3, each of the quantified measurement influences is converted to one standard deviation or standard uncertainty equivalent.

The uncertainty of the standard weights is taken to be equal to the tolerance of the OIML Class $\mathrm{E}_{1}$ weights. This uncertainty component fits a uniform probability distribution, so use of the equation $0.577 \mathrm{x}$ tolerance is appropriate. Thus, the standard uncertainty, $\mathrm{u}_{\mathrm{s}}$, due to the tolerance of the calibrated weights is:

$0.577 \times 0.15=0.08655 \mathrm{mg}$ at $200 \mathrm{~g}$, and

$0.577 \times 0.030=0.01731 \mathrm{mg}$ at $50 \mathrm{~g}$.

Because the measured standard deviation was equal to zero and this is statistically not possible, the Guide to the Expression of Uncertainty in Measurement provides guidance for this situation. Basically, the writers of the GUM state that even though there is no indicated difference in the readings due to the inability of the weighing device to detect the difference between two values, e.g., 1.55 and 2.45, each cause an indication of 2, there is still a variability associated with the indications. The writers of the GUM recommend that the standard deviation, $\mathrm{s}_{\mathrm{p}}$, be estimated as: $0.29 \times 1 \mathrm{mg}=0.29 \mathrm{mg}$.

5. Calculate the combined standard uncertainty, $\mathbf{u}_{c}$, using the equation

$$
u_{c}=\sqrt{u_{s}^{2}+s_{p}^{2}}
$$

For this example

$$
\begin{aligned}
& u_{c 200 g}=\sqrt{0.08655 \mathrm{mg}^{2}+0.29 \mathrm{mg}^{2}} \\
& u_{c 200 g}=0.3026398891 \mathrm{mg} \\
& u_{c 50 g}=\sqrt{0.01731 \mathrm{mg}^{2}+0.29 \mathrm{mg}^{2}} \\
& u_{c 50 g}=0.2905161546 \mathrm{mg}
\end{aligned}
$$

\section{Calculate the Expanded Uncertainty}

Multiply the combined standard uncertainty, $\mathrm{u}_{\mathrm{c}}$, by the coverage or ' $\mathrm{k}$ ' factor to calculate the expanded uncertainty. 


\section{Chapter 6:}

Sample Calculations and Recommendations for Reducing Uncertainty

For $\mathrm{U}_{200 \mathrm{~g},}$

\begin{tabular}{|l|l|l|l|l|}
\hline Description & Identifier & $\begin{array}{c}\text { Estimated } \\
\text { value }\end{array}$ & $\begin{array}{c}\text { Distribution } \\
\text { type }\end{array}$ & $\begin{array}{l}\text { Estimated Standard } \\
\text { Uncertainty }\end{array}$ \\
\hline Uncertainty of the weights used & $\mathrm{u}_{\mathrm{s}}$ & $0.15 \mathrm{mg}$ & Uniform & $0.08655 \mathrm{mg}$ \\
\hline $\begin{array}{l}\text { Standard deviation of the process } \\
\text { (repeatability or reproducibility) }\end{array}$ & $\mathrm{s}_{\mathrm{p}}$ & $1 \mathrm{mg}$ & Uniform & $0.29 \mathrm{mg}$ \\
\hline
\end{tabular}

\begin{tabular}{|l|l|}
\hline Combined standard uncertainty & $0.3026398891 \mathrm{mg}$ \\
\hline$u_{c}=\sqrt{u_{s}^{2}+s_{p}^{2}}$ & \\
\hline
\end{tabular}

\begin{tabular}{|l|l|}
\hline Expanded uncertainty & $0.61 \mathrm{mg}$ (at $200 \mathrm{~g})$ \\
\hline $\mathrm{U}=\mathrm{k}\left(\mathrm{u}_{\mathrm{c}}\right), \mathrm{k}=2$ (rounded to two significant digits) & 0.61 \\
\hline
\end{tabular}

and

For $\mathrm{U}_{50 \mathrm{~g}}$,

\begin{tabular}{|l|l|l|l|l|}
\hline Description & Identifier & $\begin{array}{c}\text { Estimated } \\
\text { value }\end{array}$ & $\begin{array}{c}\text { Distribution } \\
\text { type }\end{array}$ & $\begin{array}{l}\text { Estimated Standard } \\
\text { Uncertainty }\end{array}$ \\
\hline Uncertainty of the weights used & $\mathrm{u}_{\mathrm{s}}$ & $0.030 \mathrm{mg}$ & Uniform & $0.01731 \mathrm{mg}$ \\
\hline $\begin{array}{l}\text { Standard deviation of the process } \\
\text { (repeatability or reproducibility) }\end{array}$ & $\mathrm{s}_{\mathrm{p}}$ & $1 \mathrm{mg}$ & Uniform & $0.29 \mathrm{mg}$ \\
\hline
\end{tabular}

Combined standard uncertainty

\begin{tabular}{|l|l|}
\hline$u_{c}=\sqrt{u_{s}^{2}+s_{p}^{2}}$ & $0.2905161546 \mathrm{mg}$ \\
\hline
\end{tabular}

\section{Expanded uncertainty}

$\mathrm{U}=\mathrm{k}\left(\mathrm{u}_{\mathrm{c}}\right), \mathrm{k}=2$ (rounded to two significant digits)

$0.58 \mathrm{mg}($ at $50 \mathrm{~g})$

\section{Evaluate $U$ for appropriateness}

Several criteria should be evaluated.

Does the expanded uncertainty make sense?

Since the largest single standard uncertainty is $0.29 \mathrm{mg}$, it would not make sense to have an expanded uncertainty of $0.1 \mathrm{mg}$, when using a $\mathrm{k}=2$ expanded uncertainty, because $2 \times 0.29 \mathrm{mg}=$ $0.58 \mathrm{mg}$. The expanded uncertainty must always be at least $\mathrm{k}$ times the largest single uncertainty contribution included in the calculations.

Likewise, an expanded uncertainty of $50 \mathrm{mg}$ would not make sense, since no single factor approached $25 \mathrm{mg}$. The service technician must think!

Does the calculated uncertainty seem reasonable for the balance being tested?

If the balance has $1 \mathrm{mg}$ divisions, an expanded uncertainty of $28 \mathrm{mg}$ or 28 divisions would probably not be reasonable. Repair of the device and verification of the calculations is recommended. If the 


\section{Chapter 6: \\ Sample Calculations and Recommendations for Reducing Uncertainty}

balance has $10 \mathrm{mg}$ divisions, $28 \mathrm{mg}$ might be appropriate, but the calculations should be reviewed for correctness. The service technician must think!

\section{Does the expanded uncertainty meet the criteria for the calibration process?}

NIST Handbook 44 Fundamental considerations states that "if the standard is to be used without correction, its error should be not greater than one-third of the smallest tolerance to be applied when the standard is used." Interpreting this statement to indicate that the uncertainty of the calibration process should not be greater than one-third of the smallest tolerance to be applied to the device being tested, is the expanded uncertainty less than one-third of the tolerance for the balance being tested?

\begin{tabular}{|l|l|l|l|l|}
\hline Applied Load & $\begin{array}{l}\text { Expanded } \\
\text { Uncertainty }\end{array}$ & $\begin{array}{l}\text { HB 44 } \\
\text { Tolerance }\end{array}$ & $\mathbf{1 / 3}$ Tolerance & U < 1/3 Tolerance? \\
\hline $200 \mathrm{~g}$ & $0.61 \mathrm{mg}$ & $2 \mathrm{mg}$ & $0.66667 \mathrm{mg}$ & Yes \\
\hline $50 \mathrm{~g}$ & $0.58 \mathrm{mg}$ & $1 \mathrm{mg}$ & $0.33333 \mathrm{mg}$ & No \\
\hline
\end{tabular}

\section{Does the expanded uncertainty meet the requirements of the user's process?}

The answer to this question must come from the scale operator.

If the answer to either of the last two questions is 'NO', ways of decreasing the calibration uncertainty must be sought.

First, the uncertainty calculations must be reviewed for correctness.

Second, possible changes to the calibration process must be evaluated. Begin with the largest uncertainty contributor, working to the least significant.

For this sample calculation, the largest uncertainty contributor is the estimated standard deviation of the balance. The standard deviation was estimated using a formula based on the readability of the balance. A better method for determining the standard deviation would be to make between 20 and 90 additional measurements so that sample size was significantly increased improving the likelihood that the calculated standard deviation would be representative of the true balance performance. These additional measurements also reduce the likelihood of the calculated standard deviation being zero.

The ideal method of determining the standard deviation of a weighing device, such as was described for this example, is to have in place a process measurement assurance program (PMAP). Control charts, used in a PMAP, will provide a process standard deviation that includes all process measurement variables, including the effects of surrounding equipment, operator training, and environmental effects. When this example was described, it was mentioned that the fume hood fan was turned off, and that other equipment with great potential influence on the measurement were removed from the fume hood for the calibration. This created a false environment for calibration that will not be present during use which makes the calibration uncertainty not applicable to normal balance use. The user is required to calculate an uncertainty for the balance in his process, for which the reported calibration uncertainty would be only one component. 


\section{Chapter 6:}

\section{Sample Calculations and Recommendations for Reducing Uncertainty}

\section{Reporting Uncertainty}

The uncertainty statement of the balance calibration should include sufficient information that a person not associated with the calibration will understand what uncertainty components were included, how and why. The following is a sample:

"The $\mathrm{k}=2$ Expanded Uncertainty of the balance calibration was as described in the following table.

\begin{tabular}{|c|c|}
\hline Applied Load & $\begin{array}{c}\text { Calibration } \\
\text { Uncertainty (k= 2) }\end{array}$ \\
\hline $200 \mathrm{~g}$ & $0.61 \mathrm{mg}$ \\
\hline $50 \mathrm{~g}$ & $0.58 \mathrm{mg}$ \\
\hline
\end{tabular}

The uncertainty values were determined by using the root-sum-squared (RSS) combination of the significant measurement influences. Included are:

the estimated standard deviation of the scale, estimated from the size of the scale division (d), and the uncertainty of the calibrated mass standards, estimated from the allowable calibration tolerance of the weights,

The RSS combined value was multiplied by a coverage factor $(\mathrm{k})$ of 2 to obtain a value fitting the probability distribution for a $95 \%$ confidence interval."

Typically, the balance user must use the reported calibration expanded uncertainty as one component of the normal weighing operation process uncertainty.

However, if the calibration uncertainty calculation is based on the process control chart data obtained during normal use conditions, the user does not need to perform additional uncertainty calculations for his process, provided that the PMAP (Process Measurement $\underline{\text { Assurance }}$ Program) measurements are continued and properly evaluated.

\section{Sample Uncertainty Calculation \#2: (Relates to Chapter 4)}

The following example uncertainty calculation, at a single test load of $20000 \mathrm{~kg}$, for a portion of the test of a $50000 \mathrm{~kg}$ Class IIIL scale in an uncontrolled environment will discuss some of the thought processes that must be used to analyze a scale calibration and evaluate the associated uncertainty.

This scale has a capacity of $50000 \mathrm{~kg}$, with $10 \mathrm{~kg}$ divisions. The service personnel have only $10000 \mathrm{~kg}$ of NIST Class F calibrated weights available to perform the calibration. Thus, $10000 \mathrm{~kg}$ of substitution weight will be used as part of the calibration process at this sample load. On the day of the test, the location of the scale and the breezes blowing at the time cause the scale indications to be unstable, cycling randomly over a total range of approximately $40 \mathrm{~kg}$, but centered around the applied nominal value. The temperature of the scale varies $10^{\circ} \mathrm{C}$ during the calibration process as the sun warms the scale deck and, to save time, no discrimination test is performed. The scale operator does not have a measurement assurance program in place, so no charted check standard values are available to evaluate the standard deviation of the scale during normal weighing operations. Additionally, the scale operator insists that the scale be down for a minimum amount of 


\section{Chapter 6:}

\section{Sample Calculations and Recommendations for Reducing Uncertainty}

time because this is the only scale available, and each hour the scale is shut down causes the loss of many dollars of revenue. Taking repeated measurements to determine the standard deviation of the scale will take eight hours, and the scale operator is unable to absorb that loss of revenue.

The tolerance being applied to this scale is for a Class IIIL scale and is based on Table 6 of NIST Handbook 44. The example scale has 5000 divisions (5 000d) and a test load will be applied that causes an indication near $40 \%$ of the indication range. (This single test load is used for demonstration purposes only. Consult the appropriate procedures for full test requirements.)

Class IIIL Maintenance Tolerance

\begin{tabular}{|l|l|}
\hline Range tested (d) & Tolerance (d) calculated from HB 44, Table 6 \\
\hline 0 to 500 & \pm 1 \\
\hline 501 to 1000 & \pm 2 \\
\hline 1001 to 1500 & \pm 3 \\
\hline 1501 to 2000 & \pm 4 \\
\hline & $\begin{array}{l}\text { Add 1d for each additional 500d or } \\
\text { fraction thereof }\end{array}$ \\
\hline
\end{tabular}

For the sample calculation, the tolerance at the applied load will be

\begin{tabular}{|l|l|}
\hline Test Load Applied & Tolerance \\
\hline $2000 \mathrm{~d}(20000 \mathrm{~kg})$ & $\pm 4 \mathrm{~d}(40 \mathrm{~kg})$ \\
\hline
\end{tabular}

How will the uncertainty of the calibration be determined?

\section{Specify the process and equation}

The indicated values of the scale loads are a function of the applied load and the associated uncertainty. A very basic statement of the measurement equation would be: Indication $=$ applied load \pm Uncertainty, or $\mathrm{y}=\mathrm{mx}+\mathrm{b} \pm \mathrm{U}$. Uncertainty equals

$U=2 * \sqrt{u_{s}^{2}+s_{p}^{2}+u_{w}^{2}+u_{s u b}^{2}+u_{t}^{2}+u_{1}^{2}+u_{2}^{2}+u_{3}^{2}+\ldots .+u_{i}^{2}}$

\section{Identify and characterize the uncertainty sources}

The uncertainty sources that are significant for this calibration are:

the uncertainty of the standard weights, the standard deviation of the scale, the instability of the indicated value due to wind effects, the use of substitution load during the process, and the varying temperature. 


\section{Chapter 6:}

Sample Calculations and Recommendations for Reducing Uncertainty

Significant and uncorrectable factors

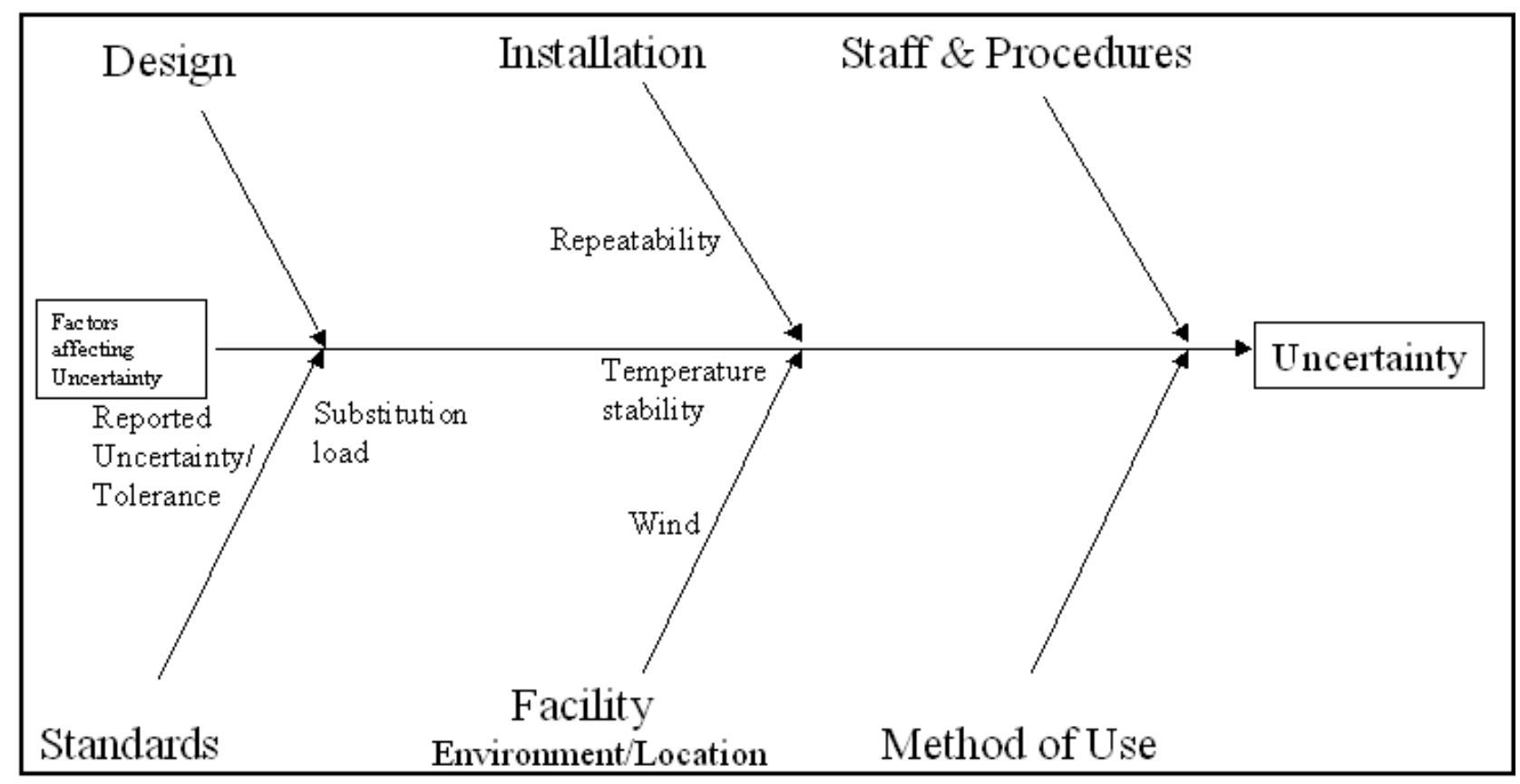

\section{Quantify the identified uncertainty components}

The uncertainty of the standard weights is taken to be equal to the tolerance of the NIST Class F weights or $1 \mathrm{~kg}$.

The temperature varies over a range of $10{ }^{\circ} \mathrm{C}$.

The indicated value varies $\pm 20 \mathrm{~kg}$.

The operator will not allow the scale to be closed for repeated measurements, the standard deviation is estimated as 0.577 times a scale division, or $5.77 \mathrm{~kg}$.

The weight of the substitution load can only be determined to the readability of the scale, so the probable uncertainty due to substitution load will be initially estimated as \pm 1 scale division.

\section{Convert the measurement influences to standard deviation equivalents}

Using the text and the Quick Guide table from Chapter 4, each of the quantified measurement influences is converted to one standard deviation or standard uncertainty equivalents.

The uncertainty of the standard weights is taken to be equal to the tolerance of the NIST Class F weights, or $1 \mathrm{~kg}$. This uncertainty component fits a uniform probability distribution, so use of the equation $0.577 \times$ tolerance, or $0.577 \times 1 \mathrm{~kg}$, is appropriate. Thus, the standard uncertainty due to the tolerance of the calibrated weights, $\mathrm{u}_{\mathrm{s}}$, is $0.577 \mathrm{~kg}$

The operator will not allow the scale to be closed for repeated measurements, so an estimate is made of the standard deviation, $\mathrm{s}_{\mathrm{p}}$, based on the $10 \mathrm{~kg}$ scale division as: $0.577 \mathrm{x} 10 \mathrm{~kg}=5.77 \mathrm{~kg}$

The indicated value varies in a range of $40 \mathrm{~kg}$ or an average indication $\pm 20 \mathrm{~kg}$.

The service technician estimates a value for the varying indication based on experience and the range over which the indication is varying, but the lack of a stable indication contributes to the uncertainty of that estimated indication. As the indication is varying 'plus' and 'minus' a fixed value 


\section{Chapter 6:}

\section{Sample Calculations and Recommendations for Reducing Uncertainty}

it will be considered to fit a uniform probability distribution. Using guidance from the table, the standard uncertainty due to the wind effects, $\mathrm{u}_{\mathrm{w}}$, is calculated as: $0.577 \times 20 \mathrm{~kg}=11.54 \mathrm{~kg}$.

The weight of the substitution load can only be determined to the readability of the scale. Assuming that the weight of the substitution load is adjusted to exactly the same indication as was generated by the calibrated load, the standard uncertainty due to the substitution load can be estimated as being equal to the repeatability of the scale. The repeatability or standard deviation of the balance was estimated to be $5.77 \mathrm{~kg}$. One occurrence of this factor must be included for each substitution load used. Only one substitution is used for the sample calculation although HB44 allows up to three substitutions in a calibration process.

Thus, the value to be included for substitution load, $\mathrm{u}_{\text {sub }}$, is $5.77 \mathrm{~kg}$.

The standard uncertainty due to the unstable scale temperature will be calculated by multiplying the scale manufacturer's temperature coefficient for the scale by the range over which the temperature is varying, $10^{\circ} \mathrm{C}$. For this example a temperature coefficient of $10 \times 10^{-6} /{ }^{\circ} \mathrm{C}$ will be used. In addition, since this coefficient is from a vendor's specification, it will typically be considered to fit a uniform probability distribution. Thus, the standard uncertainty due to varying temperature, $\mathrm{u}_{\mathrm{t}}$, is: $0.577 \mathrm{x}$ $10^{\circ} \mathrm{C} \times\left(10 \times 10^{-6} /{ }^{\circ} \mathrm{C}\right) \times 20000 \mathrm{~kg}=1.154 \mathrm{~kg}$.

\section{Calculate the combined standard uncertainty, $\mathbf{u}_{c}$, using the equation}

$$
u_{c}=\sqrt{u_{s}^{2}+s_{p}^{2}+u_{w}^{2}+u_{s u b}^{2}+u_{t}^{2}}
$$

For this example $u_{c}=\sqrt{0.577 \mathrm{~kg}^{2}+5.77 \mathrm{~kg}^{2}+11.54 \mathrm{~kg}^{2}+5.77 \mathrm{~kg}^{2}+1.154 \mathrm{~kg}^{2}}$

Therefore, $u_{c}=14.1923 \mathrm{~kg}$

\section{Calculate the Expanded Uncertainty}

Multiply the combined standard uncertainty, $\mathrm{u}_{\mathrm{c}}$, by the coverage or ' $\mathrm{k}$ ' factor to calculate the expanded uncertainty.

Therefore, $U=2 * 14.1923 \mathrm{~kg}$

$$
U=28.3846 \mathrm{~kg}
$$

which is presented as $28 \mathrm{~kg}$ when properly rounded to two significant digits. 


\section{Chapter 6:}

Sample Calculations and Recommendations for Reducing Uncertainty

\begin{tabular}{|l|l|l|l|l|}
\hline Description & Identifier & $\begin{array}{c}\text { Estimated } \\
\text { value }\end{array}$ & $\begin{array}{c}\text { Distribution } \\
\text { type }\end{array}$ & $\begin{array}{l}\text { Estimated Standard } \\
\text { Uncertainty }\end{array}$ \\
\hline Uncertainty of the weights used & $\mathrm{u}_{\mathrm{s}}$ & $1 \mathrm{~kg}$ & Uniform & $0.577 \mathrm{~kg}$ \\
\hline $\begin{array}{l}\text { Standard deviation of the process } \\
\text { (repeatability or reproducibility) }\end{array}$ & $\mathrm{s}_{\mathrm{p}}$ & $10 \mathrm{~kg}$ & Uniform & $5.77 \mathrm{~kg}$ \\
\hline Uncertainty due to wind effects & $\mathrm{u}_{\mathrm{w}}$ & $20 \mathrm{~kg}$ & Uniform & $11.54 \mathrm{~kg}$ \\
\hline $\begin{array}{l}\text { Uncertainty due to substitution } \\
\text { loads }\end{array}$ & $\mathrm{u}_{\mathrm{sub}}$ & $10 \mathrm{~kg}$ & Uniform & $5.77 \mathrm{~kg}$ \\
\hline $\begin{array}{l}\text { Uncertainty due to temperature } \\
\text { variations }\end{array}$ & $\mathrm{u}_{\mathrm{t}}$ & $10^{\circ} \mathrm{C}$ & Uniform & $1.154 \mathrm{~kg}$ \\
\hline
\end{tabular}

\begin{tabular}{|l|l|}
\hline Combined standard uncertainty & $14.1923 \mathrm{~kg}$ \\
\hline$u_{c}=\sqrt{u_{s}^{2}+s_{p}^{2}+u_{w}^{2}+u_{s u b}^{2}+u_{t}^{2}}$ & \\
\hline
\end{tabular}

\begin{tabular}{|l|l|}
\hline Expanded uncertainty & $28 \mathrm{~kg}$ \\
\hline $\mathrm{U}=\mathrm{k}\left(\mathrm{u}_{\mathrm{c}}\right), \mathrm{k}=2$ (rounded to two significant digits) & \\
\hline
\end{tabular}

\section{Evaluate $U$ for appropriateness}

Several criteria should be evaluated.

\section{Does the expanded uncertainty make sense?}

Since the largest single standard uncertainty is $11.54 \mathrm{~kg}$, as in the example, it would not make sense to have an expanded uncertainty of $20 \mathrm{~kg}$, when using a $\mathrm{k}=2$ expanded uncertainty, as

$2 \times 11.54=23.08$. The expanded uncertainty must always be at least $\mathrm{k}$ times the largest single uncertainty contribution included in the calculations.

Likewise, an expanded uncertainty of $280 \mathrm{~kg}$ would not make sense, as no single factor approached $140 \mathrm{~kg}$. The service technician must think!

\section{Does the calculated uncertainty seem reasonable for the scale being tested?}

If the scale has $1 \mathrm{~kg}$ divisions and the expanded uncertainty is calculated to be $28 \mathrm{~kg}$ or 28 divisions, there is probably something wrong, either with the scale or the uncertainty calculations. If the scale had $100 \mathrm{~kg}$ divisions, $28 \mathrm{~kg}$ might be appropriate, though the calculations should be reviewed for correctness. The service technician must think!

\section{Does the expanded uncertainty meet the criteria for the calibration process?}

NIST Handbook 44, Appendix A, "Fundamental Considerations" states that "if the standard is to be used without correction, its error should be not greater than one-third of the smallest tolerance to be applied when the standard is used." This statement has also been interpreted to mean that the uncertainty of the calibration process should not be greater than one-third of the smallest tolerance to be applied to the device being tested. Is the expanded uncertainty less than one-third of the tolerance for the scale being tested? In this sample calculation the calculated uncertainty at 20000 $\mathrm{kg}$ is $28 \mathrm{~kg}$, and the tolerance at $20000 \mathrm{~kg}$ is $40 \mathrm{~kg}$, thus one-third of the tolerance equals $13.33 \mathrm{~kg}$. $28 \mathrm{~kg}$ is greater than $13.33 \mathrm{~kg}$ so the correct response to the question is "NO".

\section{Does the expanded uncertainty meet the requirements of the user's process?}




\section{Chapter 6: \\ Sample Calculations and Recommendations for Reducing Uncertainty}

The answer to this question must come from the scale operator. The scale operator must be knowledgeable about the uncertainty requirements for his situation, whether for NIST HB44 tolerances or other regulatory requirements.

If the answer to either of the last two questions is 'NO', ways of decreasing the calibration uncertainty must be sought.

First, the uncertainty calculations must be reviewed for correctness.

Are there any mathematical errors?

Second, evaluate possible changes to the calibration process.

Begin with the largest uncertainty contributor, working to the least significant.

In the sample calculation, the effect of the wind and air currents on the scale performance are the largest contributor. Rescheduling the test on a calm day would have an associated cost but eliminating the effect of wind and air currents by re-scheduling could reduce the expanded uncertainty to $17 \mathrm{~kg}$ by reducing the $\mathrm{u}_{\mathrm{w}}$ value in the calculation from $11.54 \mathrm{~kg}$ to $0 \mathrm{~kg}$.

The next most significant uncertainty contributor is the estimated standard deviation of the scale. If a discrimination test were performed, the equation $\mathrm{s}_{\mathrm{p}}=0.29 d$ could be used, reducing the standard deviation estimate, $\mathrm{s}_{\mathrm{p}}$, by a factor of almost two. The expanded uncertainty would further decrease to $8.6 \mathrm{~kg}$ which would meet the requirements of HB 44 . Potentially, performing a series of measurements and calculating the standard deviation of seven or more measurement results could reduce the standard deviation even more, though the potential does exist that the true standard deviation is larger than the estimate. But, there is an associated cost in labor and loss of use of the scale during the time required for the additional test.

A related uncertainty contributor is the use of substitution loads, since the contribution of the substitution process is based on the standard deviation of the scale. If $20000 \mathrm{~kg}$ of calibrated load were used to test the scale instead of using $10000 \mathrm{~kg}$ of substitution load, the uncertainty would be further reduced to $6.5 \mathrm{~kg}$.

By addressing the three largest uncertainty contributors the expanded uncertainty has been reduced by a factor of four, from $28 \mathrm{~kg}$ to $6.5 \mathrm{~kg}$. While this may not be typical of all scale calibration uncertainties, significant reductions are often possible. The cost vs. benefit must be evaluated for each situation, based on the requirements and use of the weighing device.

Third, repair, relocation or replacement of the scale might be considered.

Is the large uncertainty due to location or maintenance issues that can be corrected? Large uncertainties may be the result of an influence that has a constant effect on the measurement results, e.g., a vibration source that is always present when the scale is being used or calibrated. But they can also be random events that are unnoticed except for their influence on the scale operation. This can be especially true in an industrial environment where heavy equipment, rock crushers, trains, ovens, machinery, etc. are in constant use near the scale. In this situation, moving the scale must be considered as one option. The service technician must be aware of 


\section{Chapter 6: \\ Sample Calculations and Recommendations for Reducing Uncertainty}

potential sources of measurement errors and take appropriate action to minimize their influence on the measurement results.

The process changes required to reduce the calibration uncertainty must be a collaborative effort between the service personnel and the scale operator in order for the resulting reduced calibration uncertainty to remain valid.

And remember, uncertainty calculations must be performed for each calibration load as different tolerances will apply to the calibrated weights, and different test loads may incorporate fewer or additional substitution loads.

\section{Reporting Uncertainty}

The uncertainty statement of the scale calibration should include sufficient information that a person not associated with the calibration will understand what uncertainty components were included, how and why. The following is a sample:

"The $\mathrm{k}=2$ Expanded Uncertainty of the described scale calibration was $\pm 28 \mathrm{~kg}$ at $20000 \mathrm{~kg}$. This value was determined by using the root-sum-squared (RSS) combination of the significant measurement influences. Included are:

the standard deviation of the scale estimated from the size of the scale division (d); the uncertainty of the calibrated mass standards estimated from the allowable calibration tolerance of the weights; the effects of instability due to air currents; the potential effects of temperature variations during the test; and the effect of using substitution load estimated from the repeatability of the scale.

The RSS combined value was multiplied by a coverage factor $(\mathrm{k})$ of 2 to obtain a value fitting the probability distribution for a $95 \%$ confidence interval."

(When multiple loads are applied with differing calculated uncertainty values, it may be necessary to use a table format as part of the uncertainty statement.)

Typically, the scale operator must use the reported calibration expanded uncertainty(ies) as one component of the normal weighing operations process uncertainty(ies). However, if service personnel were provided a measured $s_{p}$ value, calculated from the results of measurements of a check standard used in the normal weighing process, the reported expanded uncertainty would be the uncertainty associated with the normal weighing process. But this is true only if the $\mathrm{s}_{\mathrm{p}}$ value was determined by measurement results for a check standard.

\section{Reducing Process Variability}

Measurement uncertainty is largely dependent on the environment in which a scale or balance is used or proper use of the weighing device (operator effects). The single greatest uncertainty contributor for a weighing device is typically the variability or repeatability of the device. Except for some unique situations involving balances with very small capacities, mass standards can be selected so that the uncertainty due to the standards is relatively insignificant. Thus, the area of concentration when attempting to reduce uncertainty must be those factors that contribute to the 


\section{Chapter 6: Sample Calculations and Recommendations for Reducing Uncertainty}

variability of the weighing device. The factors which most affect variability are normally environmental in nature, involving vibration, temperature and humidity. Additional measurement influences affecting variability include operator training, skill and attitude, air currents, product contamination, etc. Appropriate steps must be taken to minimize these measurement influences if improved balance or scale uncertainties are to result.

\section{Changes Needed in Current Calibration Procedures to Address Uncertainty}

The current selection of available scale and balance calibration procedures includes:

- OIML R 76-1, "Nonautomatic weighing instruments, Part1: Metrological and technical requirements-Tests",

- ASTM E 319-85, "Standard Practice for the Evaluation of Single-Pan Mechanical Balances",

- ASTM E 898-88, "Standard Method of Testing Top-Loading, Direct-Reading Laboratory Scales and Balances",

- ASTM E 1270-88, "Standard Test Method for Equal-Arm Balances";

- NIST Handbook 44, "Specifications, Tolerances, and Other Technical Requirements for Weighing and Measuring Devices", and

- NIST Handbook 112, "Examination Procedure Outlines for Commercial Weighing and Measuring Devices."

These procedures do not address the issue of calibration uncertainty in any manner except for a requirement in $\mathrm{R}$ 76-1, 3.7.1 Weights, that

"The standard weights or standard masses used for the verification of an instrument shall not have an error greater than 1/3 of the maximum permissible error of the instrument for the applied load." and a similar requirement in HB 44, Appendix A, Fundamental Considerations, that "The error in a standard used by a weights and measures official should be known and corrected for when the standard is used; or if the standard is to be used without correction, its error should be not greater than one-third of the smallest tolerance to be applied when the standard is used."

This lack of direction in the procedures has led to a general disregard of the issue of uncertainty in scale and balance calibrations for many years. Some regulatory bodies have attempted to address this issue but, in most cases, have not provided sufficient guidance to enable users to properly and accurately assess the uncertainty of their weighing devices.

It should be noted that the common practice of stating the tolerance of the applied standard masses as the uncertainty of a scale or balance calibration is not acceptable because it does not comply with the requirement of ISO/IEC 17025 for a documented uncertainty analysis and does not include all known measurement influences.

Though it is desired that a thorough discussion of uncertainty contributors be included in these procedures, including specific methodologies for evaluation and calculation of the calibration uncertainty, it is strongly recommended that the responsible standards writing organizations include, as a minimum, a rudimentary analysis of the measurement influences that contribute to process uncertainties. Without an uncertainty analysis resulting in a stated measurement uncertainty, the measurement results are just numbers on a page. They have no chance of being traceable, as traceability requires an unbroken chain of comparisons, all having stated uncertainties. 


\section{Appendix A}

\section{Common Terminology and Definitions}

\section{Appendix A \\ Common Terminology and Definitions}

Accuracy Class (VIM 5.19): class of measuring instruments that meet certain metrological requirements that are intended to keep errors within specified limits.

Note: Usually denoted by a number or symbol adopted by convention and called the class index.

Accuracy of measurement (VIM 3.5): closeness of agreement between the result of a measurement and a true value of the measurand.

Calibration (VIM 6.11): Set of operations that establish, under specified conditions, the relationship between values of quantities indicated by a measuring instrument or measuring system, or values represented by a material measure or a reference material, and the corresponding values realized by standards.

Notes:

1) the result of a calibration permits either the assignment of values of measurands to the indications or the determination of corrections with respect to indications.

2) A calibration may also determine other metrological properties such as the effect of influence quantities.

3) The result of a calibration may be recorded in a document, sometimes called a calibration certificate or a calibration report.

Combined standard uncertainty (GUM): standard uncertainty of the result of a measurement when that result is obtained from the values of a number of other quantities, equal to the positive square root of a sum of terms, the terms being the variances or covariances of these other quantities weighted according to how the measurement result varies with changes in the quantities. (Author): The combined standard uncertainty and the method of calculation is explained in this Recommended Practice Guide and is typically the result of the RSS combining of the values from the uncertainty contributors. The combined standard uncertainty is the value multiplied by the coverage factor $(\mathrm{k})$ to obtain the expanded uncertainty.

Corner load or 'off-center' error (ASTM E 898): differences in indicated weight when a sample weight is shifted to various positions on the weighting area of the sample pan.

Coverage factor (k factor) (GUM): numerical factor used as a multiplier of the combined standard uncertainty in order to obtain an expanded uncertainty

Note: a coverage factor, $\mathrm{k}$, is typically in the range of 2 to $3 . \mathrm{k}=2$ is the standard coverage factor to be used. It defines a confidence interval of approximately $95 \%$. The use of other coverage factors requires justification of the reason for use.

Discrimination (threshold) (VIM 5.11): The largest change in a stimulus that produces no detectable change in the response of a measuring instrument, the change in the stimulus taking place slowly and monotonically.

Expanded uncertainty (GUM): quantity defining an interval about the result of a measurement that may be expected to encompass a large fraction of the distribution of values that could reasonably be attributed to the measurand

Notes:

1) the fraction may viewed as the coverage probability or level of confidence of the interval 


\section{Appendix A}

\section{Common Terminology and Definitions}

2) to associate a specific level of confidence with the interval defined by the expanded uncertainty requires explicit or implicit assumptions regarding the probability distribution characterized by the measurement result and its combined standard uncertainty. The level of confidence that may be attributed to this interval can be known only to the extent to which such assumptions may be justified.

Experimental Standard deviation (VIM 3.8): for a series of $n$ measurements of the same measurand, the quantity ' $\mathrm{s}$ ' characterizing the dispersion of the results and given by the formula:

$s=\sqrt{\frac{\sum_{i=1}^{n}\left(x_{i}-\bar{x}\right)^{2}}{n-1}}$ with $x_{\mathrm{i}}$ being the result of the $i$ th measurement and $\bar{x}$ being the arithmetic mean of the $n$ results considered.

Independent Variables (Author): a property of two or more values where the value of each is not related to or dependent on any portion of another.

Influence Quantity (VIM 2.7): quantity that is not the measurand, but that affects the result of the measurement.

Example: Ambient air temperature

Linearity error (ASTM E 898): the degree to which a graph of weight values indicated by a scale vs. the true values of the respective test weights approximates a straight line.

(Author): error caused by deviations of an indicator from a constant sensitivity, with changing load.

Mass Correction: value algebraically added to the nominal mass value to obtain the calibrated mass value of a mass artifact.

(Author's interpretation of definition given in ASTM E 617.)

Measurand (VIM 2.6): particular quantity subject to measurement.

Normal distribution (paraphrased from the on-line NIST Engineering Statistical Handbook): Distribution function for which one value (the mean) has a greater probability of occurrence than all other values. A normal distribution can be estimated with the sample mean and sample standard deviation.

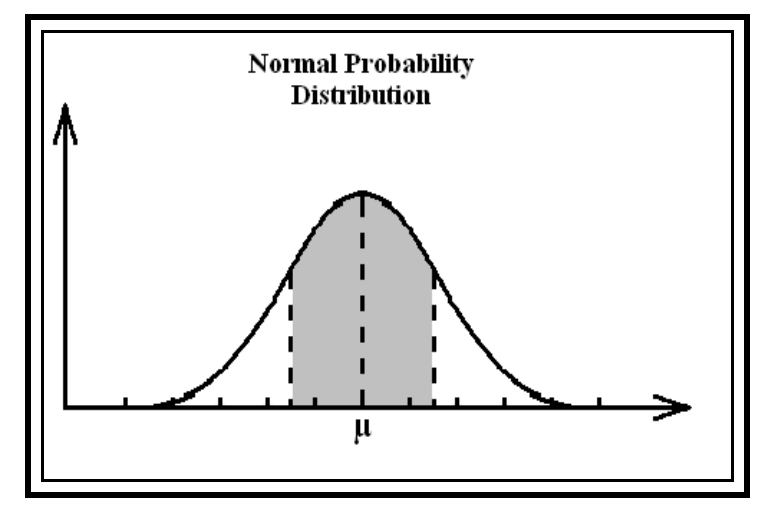




\section{Appendix A}

\section{Common Terminology and Definitions}

The normal distribution is commonly described as being a bell shaped distribution. Note that the mean, $\mu$, is the most probable value.

Probability (The American Heritage ${ }^{\circledR}$ Dictionary of the English Language: Fourth Edition): 3. The likelihood that a given event will occur.

Statistics: A number expressing the likelihood that a specific event will occur, expressed as the ratio of the number of actual occurrences to the number of possible occurrences.

Rectangular distribution: See Uniform distribution.

Repeatability (VIM 5.27): closeness of agreement between the results of successive measurements of the same measurand carried out under the same conditions of measurement.

Note: 'Same conditions' includes the same procedure, same observer, same measuring instrument, same location, with repetition over a short period of time.

Reproducibility (VIM 3.7): Closeness of agreement between the results of measurements of the same measurand carried out under changed conditions of measurement.

Resolution (VIM 5.12): Smallest difference between indications of a displaying device that can be meaningfully distinguished.

Note: for a digital displaying device this is the change in the indication when the least significant digit changes by one step.

Scale Division, value of (d) (HB 44): the value of the scale division, expressed in units of mass, is the smallest subdivision of the scale for analog indication or the difference between two consecutively indicated values for digital indication.

Sensitivity (VIM 5.10): change in the response of a measuring instrument divided by the corresponding change in the stimulus, for example: 10 grams per division.

Service Personnel: used in this guide to identify the skilled personnel who repair, calibrate or service scales and balances, primarily in the field environment.

Stability (VIM 5.14): the ability of a measuring instrument to maintain constant its metrological characteristics with time.

Standard: For the purposes of this document, 'standard' refers to the calibrated weight artifact used to apply a known load to a weighing device. The word 'standard' is used in other circumstances to describe a prescriptive document containing specifications to which a device must conform.

Standard Uncertainty (GUM): Uncertainty of the result of a measurement expressed as one standard deviation.

Strain-Load Test (HB 44): The test of a scale beginning with the scale under load, applying known test weights to determine accuracy over a portion of the weighing range, not beginning at a zero indication. 


\section{Appendix A}

\section{Common Terminology and Definitions}

Substitution Load: quantity of material applied to a scale to cause a duplicate scale indication to that generated by known test weights. The known test weights can then be added with the substitution load, effectively multiplying the known load. Additional uncertainty results from the use of substitution loads. The substitution process can be repeated several times (limited to no more than three substitutions by HB 44, Table 4), which requires additional uncertainty to be included for each substitution.

Tolerance (NIST HB 44): A value fixing the limit of allowable error or departure from true performance or value.

Traceability (VIM 6.10): property of the result of a measurement of the value of a standard whereby it can be related to stated references, usually national or international standards, through an unbroken chain of comparisons all having stated uncertainties.

Note: the unbroken chain of comparisons is called a traceability chain.

Uncertainty of measurement (VIM 3.9): parameter, associated with the result of a measurement, that characterizes the dispersion of the values that could reasonably be attributed to the measurand. Notes:

1) The parameter may be, for example, a standard deviation (or a given multiple of it), or a half-width of an interval having a stated level of confidence.

2) Uncertainty of measurement comprises, in general, many components. Some of these components may be evaluated from the statistical distribution of the results of series of measurements and can be characterized by experimental standard deviations. The other components, which can also be characterized by standard deviation, are evaluated from assumed probability distributions based on experience or other information.

3) It is understood that the result of the measurement is the best estimate of the value of the measurand, and that all components of uncertainty, including those arising from systematic effects, such as components associated with corrections and reference standards, contribute to the dispersion.

Uncertainty (The American Heritage ${ }^{\circledR}$ Dictionary of the English Language, Fourth Edition): "Statistical: The estimated amount or percentage by which an observed or calculated value may differ from the true value.

SYNONYMS: doubt, dubiety, skepticism, suspicion, mistrust. These nouns refer to the condition of being unsure about someone or something."

Uniform distribution (paraphrased from the on-line NIST Engineering Statistical Handbook): Distribution function where any value within the range of the function is equally probable. 


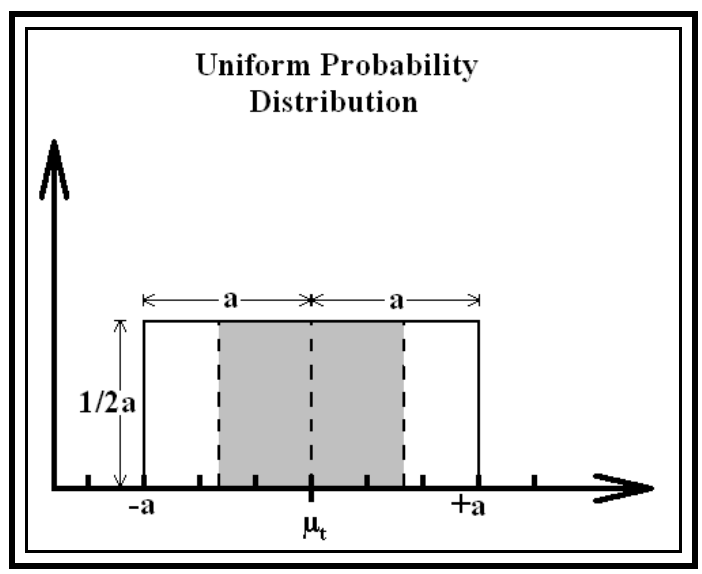

Sometimes called a rectangular distribution due to its rectangular shape. This distribution function is considered the most conservative estimate of uncertainty, i.e., it gives the largest standard deviation.

Verification scale division, value of (e) (HB 44): a value expressed in units of weight (mass) and specified by the manufacturer of a device, by which the tolerance values and the accuracy class applicable to the device are determined. The verification scale division, e, may be different from the displayed scale division, $\mathrm{d}$, for certain devices used for weight classifying or weighing in predetermined amounts and certain class I and II scales.

(The value of ' $e$ ' may be set by the denomination of the smallest possible weight, typically 1 milligram, especially when the value of ' $d$ ' is less than 1 milligram.) 
Appendix A

Common Terminology and Definitions 


\section{Appendix B}

\section{Bibliography}

\section{Appendix B}

Bibliography

American Society for Testing and Materials (ASTM) E 319 - 85, "Standard Practice for the Evaluation of Single-Pan Mechanical Balances", ASTM, 1997

American Society for Testing and Materials (ASTM) E 898 - 88, "Standard Method of Testing TopLoading, Direct-Reading Laboratory Scales and Balances", ASTM, 2000

American Society for Testing and Materials (ASTM) E 1270 - 88, "Standard Test Method for Equal Arm Balances", ASTM, 1997

American Society for Testing and Materials (ASTM) E 617 - 97, "Standard Specification for Laboratory Weights and Precision Mass Standards", ASTM, 1997

American National Standards Institute/National Conference of Standards Laboratories International (ANSI/NCSLI) Z540-2-1997 "U.S. Guide to the Expression of Uncertainty in Measurement", ANSI/NCSLI, 1997

Arthur Reichmuth, "Influence Sources and Prevention in Weighing", Mettler Toledo, Oct 1999

Arthur Reichmuth, "Non-linearity of Laboratory Balances and Its impact on Uncertainty", 2000 NCSL Workshop and Symposium, 2000

Deutscher Kalibrierdienst, DKD-R-7-1, Issue 98, "Calibration of Non-Automatic Electronic Weighing Instruments", DKD, 1998

EURACHEM/CITAC Guide, “Quantifying Uncertainty in Analytical Measurement”, EURACHEM/CITAC, 2000

Georgia Harris, "Ensuring Accuracy and Traceability of Weighing Instruments", ASTM Standardization News, 21(4): 44-51, 1993

Georgia Harris, "Implementation of the Guide to the Expression of Uncertainty in Measurement for State Calibration Laboratories", 1994 NCSL Workshop \& Symposium, 1994

Houghton Mifflin Company, The American Heritage ${ }^{\circledR}$ Dictionary of the English Language, Fourth Edition., Houghton Mifflin Company, 2000

International Organization for Standardization, "Guide to the Expression of Uncertainty in Measurement”, (GUM), International Organization for Standardization, 1993

International Organization for Standardization, "General requirements for the Competence of Testing and Calibration Laboratories", ISO/IEC 17025:, International Organization for Standardization, 1999 


\section{Appendix B \\ Bibliography}

International Organization for Standardization, "International Vocabulary of Basic and General Terms in Metrology (VIM)", International Organization for Standardization, 1993

Jerry Everhart, "Determining Mass Measurement Uncertainty", Cal Lab, May/June 1995

Mettler-Toledo, "Fundamentals of Mass Determination", Mettler-Toledo AG, 1991

National Conference on Weights and Measures Publication 14, "National Type Evaluation Program, Administrative Procedures, Technical Policy, Checklists, and Test Procedures", National Conference on Weights and Measures, 2002

National Conference of Standards Laboratories Recommended Practice RP-12 "Determining \& Reporting Measurement Uncertainties," National Conference of Standards Laboratories International, 1995

National Institute of Standards and Technology Technical Note 1297, 1994 Edition, "Guidelines for Evaluating and Expressing the Uncertainty of NIST Measurement Results", National Institute of Standards and Technology, 1994

National Institute of Standards and Technology Handbook 44, "Specifications, Tolerances, and Other Technical Requirements for Weighing and Measuring Devices," NIST, 2002

NIST/SEMATECH e-Handbook of Statistical Methods, http://www.itl.nist.gov/div898/handbook/, 2001

National Institute of Standards and Technology Handbook 112, "Examination Procedure Outlines for Commercial Weighing and Measuring Devices", National Institute of Standards and Technology, 2002

National Institute of Standards and Technology Handbook 105-1, " Specifications and Tolerances for Reference Standards and Field Standard Weights and Measures, 1. Specifications and Tolerances for Field Standard Weights (NIST Class F)", National Institute of Standards and Technology, 1990

Organisation Internationale de Métrologie Légale (OIML), OIML R 76-1, "Nonautomatic weighing instruments, Part 1: Metrological and technical requirements-Tests”, OIML, Edition 1992(E)

Organisation Internationale de Métrologie Légale (OIML), OIML R 111 Committee Draft OIML/CD R 111, "Weights of Classes $E_{1}, E_{2}, F_{1}, F_{2}, M_{1}, M_{2}, M_{3}$ ", OIML, 2002

W. J. Youden, "NIST Special Publication 672: Experimentation and Measurement", National Institute of Standards and Technology, 1997

Walter E. Kupper, Dr.scn.techn, "High Accuracy Mass Measurement, From Micrograms to Tons", ISA Transactions, (Vol 29, 4, 1990) 